\title{
The collection of Nematomorpha in the Zoological Museum Hamburg, including description of a new species, Chordodes jelkae sp. n.
}

\author{
Andreas Schmidt-Rhaesa ${ }^{1}$ \\ 1 Centrum für Naturkunde, University of Hamburg, Martin-Luther-King-Platz 3, 20146 Hamburg, Germany \\ http://zoobank.org/FAB1AD5B-087A-45AB-AFA3-8CF3513411F8 \\ Corresponding author: Andreas Schmidt-Rhaesa (andreas.schmidt-rhaesa@uni-hamburg.de)
}

\begin{abstract}
Received 31 August 2016

Accepted 31 October 2016

Published 29 November 2016

Academic editor:

Michael Ohl

\section{Key Words}

Nematomorpha

Chordodes jelkae sp. n.

horsehair worms

collection

revision

SEM

The collection of horsehair worms in the Zoological Museum of the Centrum für Naturkunde (CeNak) of the University of Hamburg has been revised. All specimens have been investigated by Scanning Electron Microscopy (SEM). A total of 173 specimens from 135 catalogue entries is present in the collection, these represent 39 species from 10 genera (Gordius, Chordodes, Paragordius, Parachordodes, Gordionus, Acutogordius, Beatogordius, Paragordionus, Pseudochordodes, Nectonema). Previous revisions of the Nematomorpha material have been done in 1893 by Römer and in 1935 by Heinze. A number of species could not be determined to species level, either because characters were not preserved well enough or because observed characters did not fit available species descriptions. This does account in particular for the genus Gordius, where diagnostic characters are few and great uncertainties exist concerning the status of certain species. Therefore, within this genus, many records were only determined as Gordius sp., including some specimens that had previously been determined to species level. One new species is described from the material of the collection. This species is named Chordodes jelkae sp. $\mathrm{n}$. and it is characterized by the presence of an apical tuft of bristles on simple areoles in combination with the absence of thorn areoles. The holotype of Chordodes pilosus Möbius, 1855 was reinvestigated, and its species identity cannot be determined unambiguously. Therefore the name Chordodes pilosus is considered a nomen dubium.
\end{abstract}

\section{Introduction}

The Zoological Museum Hamburg has a collection of 173 specimens from 135 catalogue entries of horsehair worms (Nematomorpha) representing 39 species from 10 genera. A total of about 455 species has been described from all over the world. Important for collection and determination are adult worms in their free-living phase (see Hanelt et al. 2005 and Schmidt-Rhaesa 2013 for recent summaries on the life cycle and other topics), because these are encountered most often and because the cuticle has structures that are relevant for determination. The parasitic juveniles are almost impossible to determine, because they show a different cuticle that does not contain differential structures (see, e.g., Schmidt-Rhaesa 2005).
The only published review of the collection of the Zoological Museum Hamburg is from Römer (1895). He investigated material that was included in the registry catalogue as numbers V2206 to V2234 (without giving these accession numbers in the publication). These are 29 catalogue numbers from 11 species of Gordius and Chordodes, the only genera available by that time. According to recent systematics, Römer's 10 species belong to four genera: Gordius, Gordionus, Parachordodes and Chordodes. The material of three numbers (V2206, 2210, 2219) was lost (noticed by a revision in 1954). Six numbers (V2209-V2212, 2232, V2234) turned out to be mermithid nematodes, among these are two species that were newly described (as nematomorphs) by Römer (1895): Chordodes liguligerus Römer, 1895 (see Heinze 1935a) and C. hamatus. The latter species was later renamed Gordiomermis hamatus (Heinze 1934). 
In 1935, Kurt Heinze from Berlin worked on the Hamburg collection and determined a number of specimens, a few of these results were published in Heinze (1935a). The collecting localities of several Hamburg specimens occurred in Heinze's summaries of German Nematomorpha from 1937 and 1941.

Since then, nobody has reviewed the material or deposited new type material until from 2008 on the author deposited several types in the collection.

It is the aim of this summary on the one hand to present an overview of the Nematomorpha material in the Hamburg collection and on the other hand to determine all material according to current standards. This includes investigation by Scanning Electron Microscopy (SEM). The SEM reinvestigation led to several new determinations, in particular a number of determinations at the species level could not be confirmed and hence are treated here as "sp.".

\section{Material and methods}

Specimens are conserved in ethanol with a desired concentration of $70 \%$. For the reinvestigation, entire pieces from the midbody region and in some cases the posterior end (about 1-2 $\mathrm{mm}$ from the terminal tip) were prepared for Scanning Electron Microscopy (SEM). Pieces were dehydrated in an increasing ethanol series, critically point dried and coated with gold in a sputter coater. Observation took place using a LEO SEM 1524 at $10 \mathrm{kV}$. Digital images were taken.

\section{Results and discussion}

In the Zoological Museum Hamburg, entries are recorded in a catalogue book, printed as a record card and recorded digitally in a Filemaker file. Entries in the catalogue are hand-written and could not always be read reliably. It was attempted to verify the collection localities, but this was not possible in all cases. Writing of names is given here as good as possible. Citations from the catalogue are given in quotation marks. The main focus is on the older records, which are reinvestigated. Younger records, which are well documented in the literature, are presented only briefly, with reference to the respective publications.

\section{Genus Acutogordius Heinze, 1952}

Males in species of Acutogordius have a postcloacal crescent, like in Gordius, but the tail lobes are pointed and the entire posterior end tapers towards the pointed tip of the tail lobes (Fig. 7D, G, J). Nine species have been described. The distribution of fine bristles in the male anterior end appears to be important for species delimitation, but such fine bristles were not always reported in older descriptions. See Schmidt-Rhaesa and Geraci (2006) for a summary.

\section{Acutogordius cf. acuminatus De Miralles \& De Vil-} lalobos, 1998

\section{Material examined. V 2213 (1 male). Fig. 7C-E.}

Location. Brazil, Joinville, Santa Catarina.

Remarks from the catalogue. Collected by "Killmann" (no date given). Received by the museum on June 19, 1890. Determined by Römer in 1893 as Gordius aquaticus and by Heinze in 1935 as Gordius sp.

Occurs in publications. Römer (1895, page 791), briefly in Römer (1896, page 260).

Remarks. Römer (1895) describes this specimen as corresponding to Gordius aquaticus in almost all respects, except for the absence of lightly coloured spots and the pointed shape of the posterior end. This last character was regarded diagnostic for a new genus Acutogordius, introduced by Heinze (1952). As no bristles were observed on the cuticle (Fig. 7C), the specimen is closest to Acutogordius acuminatus De Miralles \& De Villalobos, 1998, which was described from Brazil, too (De Miralles and De Villalobos 1998, see also Schmidt-Rhaesa and Geraci 2006).

Material examined. V7351(b) (1 male). Fig. 7F, G.

Location. Brazil, presumably Itapoá, Santa Catarina (see remarks from the catalogue).

Remarks from the catalogue. Collected by W. Ehrhardt on January 17, 1910. Received by the museum on November 12, 1910. As location, the catalogue says "Humboldt-Geb. am Itapoeú", some letters are not explicit. This location could not be retrieved, but Itapoá is close. Additionally, there are other catalogue entries with the same date and same collector having as location Joinville, which is close to Itapoá in the province Santa Catarina. Original determination as "Gordiide".

Occurs in publications. none

Remarks. The catalogue notes "dv", meaning "diverse" as number of specimens. 13 specimens were found, 12 of them are determined as Chordodes brasiliensis (see there) and specimen V7351(b) belongs to the genus $\mathrm{Acu}$ togordius. No bristles were observed on the body cuticle (Fig. 7F) or the posterior end (Fig. 7G), therefore the specimen is closest to the description of A. acuminatus De Miralles \& De Villalobos, 1998, which was described from Brazil, too (De Miralles and De Villalobos 1998, see also Schmidt-Rhaesa and Geraci 2006).

Material examined. V11465 (1 male). Fig. 7H-J.

Location. Brazil, Boiteuxburgo, Santa Catarina.

Remarks from the catalogue. Collected by Paul Missfeldt (date unknown). Received by the museum on December 5, 1930. Originally determined as "Gordius".

Occurs in publications. unknown

Remarks. The specimen has clearly pointed tail lobes, which carry two longitudinal crests or keels (Fig. $7 \mathrm{~J})$. These may be artificial structures, but as they occur on both tail lobes, some doubts remain. There are some scattered bristle-like structures on the cuticle, but it could 
not be determined with certainty if these are really cuticular structures (Fig. 7I). Otherwise the cuticle is smooth (Fig. 7H). As bristles are absent on the posterior end, the specimen is closest to the description of A. acuminatus De Miralles \& De Villalobos, 1998 (see above and De Miralles and De Villalobos 1998, Schmidt-Rhaesa and Geraci 2006).

\section{Genus Beatogordius Heinze, 1934}

Characteristic for this genus, which currently includes 21 species (Schmidt-Rhaesa 2013), is that areoles are arranged in longitudinal rows. Two specimens of the collection belong to Beatogordius, among them the holotype of the most recently described species in this genus.

\section{Beatogordius sp.}

Material examined. V8939 (1 male). Fig. 9A-C.

Location. Chile, Coronel, in drinking water.

Remarks from the catalogue. collected by R. Paeseler on October 5, 1914. Received by the museum on January 15, 1920. Originally determined as "Gordiide".

Occurs in publications. unknown

Remarks. The cuticle is not very well preserved and strongly covered with dirt. Paired elongate areoles arranged in longitudinal rows can be well observed (Fig. 9A), but interareolar structures were not seen. This is characteristic for the genus Beatogordius and resembles patterns found especially in B. latastei (De Villalobos et al. 2003). The posterior end has short, probably broken, spines around the cloacal opening (Fig. 9B) and postcloacal spines, which extend from posterior of the cloacal opening onto about half of the ventral side of the tail lobes (Fig. 9C). In the anterior region they are stout and gradually become more slender in the posterior region (Fig. 9D). Precloacal bristles were not observed (Fig. 9C), but it cannot be excluded that they were artificially eroded or covered by dirt. Males of all South American species have clear precloacal rows of bristles (De Villalobos et al. 2003).

Material examined. V9575 (1 male). Fig. 8I-K.

Location. Chile, Limache (writing is not explicit), in river.

Remarks from the catalogue. collected by D.C. Bock (date not given). Received by the museum on July 9, 1923. Originally determined as "Gordiide"

Occurs in publications. unknown

Remarks. The cuticle of this specimen shows longitudinal rows of paired, elongate areoles, which is characteristic for the genus Beatogordius (Fig. 8I, J). There is closest resemblance to $B$. latastei (Camerano, 1895) (compare De Villalobos et al. 2003), but for a proper determination the cuticular structures in the interareolar region should be checked, which are not seen clearly due to some covering of dirt between areoles in specimen V9575.

\section{Beatogordius chinensis Schmidt-Rhaesa, 2011}

\section{Material examined. V13294 (1 female)}

Location. China, Yunnan province, $2 \mathrm{~km}$ south of Haba, Haba Xueshan Mountains $\left(27^{\circ} 21.9^{\prime} \mathrm{N}, 100^{\circ} 08.3^{\prime} \mathrm{E}\right)$, $2870 \mathrm{~m}$. Collected in a small pond in a dry valley of a brook.

Remarks from the catalogue. Collected by J. Hájek and J. Růžička on June 17-20, 2007.

Occurs in publications. Schmidt-Rhaesa (2011)

Remarks. Holotype and only known specimen as described in Schmidt-Rhaesa (2011).

\section{Genus Chordodes Creplin, 1847}

This is a genus with almost 100 described species, most of which occur in the tropics and subtropics and many of which have mantids as host (see Schmidt-Rhaesa et al. 2008, Schmidt-Rhaesa 2013). Characteristic for the genus is a particular type of areoles, crowned areoles that has a stem with an apical "crown" of longer or shorter filaments. Areoles can be very diverse, and several types are present.

\section{Chordodes sp.}

Material examined. V2230 (1 female). Fig. 12C-G.

Location. Venezuela, Ciudad Bolivar.

Remarks from the catalogue. Collected by D. Siegert (no collection date or date when received by the museum given). Determined by Möbius in 1855 as Chordodes pilosus, confirmed by Römer in 1893 and Heinze in 1935. Host: Blabera gigantea.

Occurs in publications. Möbius (1855), Janda (1894, page 604), Römer (1895, page 797), Camerano (1897, page 416), Römer (1896, page 280), Heinze (1935a, page 24).

Remarks. This specimen is the holotype for the species Chordodes pilosus, described by Möbius in 1855 . The genus Chordodes had been introduced briefly before (Creplin 1847), and the main reason to distinguish this genus from Gordius was the abundant presence of marked areoles. Römer $(1895,1896)$ reinvestigated the specimen, but without going much further than Möbius' original description. The descriptions were not detailed enough to allow a distinction from the several new species that were described towards the end of the $19^{\text {th }}$ century, and Camerano (1897) listed $C$. pilosus under species inquirendae. Later, Heinze (1935a) reinvestigated the specimen again and added some information on the cuticle. The current reinvestigation by SEM shows that crowned areoles, the diagnostic character of the genus Chordodes, are present on the cuticle (Fig. 12C-G). Crowned areoles are arranged in clusters, surrounded by circumcluster areoles (Fig. 12F). Simple and tubercle areoles are present. All areoles are very bad in shape and appear worn or eroded, especially the filaments of the crowned areoles (Fig. $12 \mathrm{E}-\mathrm{G})$. Nevertheless it can be seen that crowned areoles 
with longer apical filaments are present along a longitudinal stretch, probably the ventral midline (Fig. 12C). All observed characters are present in many species of Chordodes and their preservation in specimen V2230 is not good enough to characterise a distinct species. Therefore, the species identity of Chordodes pilosus cannot be unambiguously determined from the type specimen, and, thus, the name must be regarded a nomen dubium.

Material examined. V5320 (1 male, 1 female). Fig. 12H-O. Location. South Africa, Bothaville.

Remarks from the catalogue. Collected by Brauns (no date given). Received by the museum on November 13, 1899. Determined as "Gordius". From "Mantis".

Occurs in publications. unknown

Remarks. The cuticle of the female is in comparably bad shape. Crowned areoles with short and long apical filaments are present (Fig. 12H-K). Tubercle, thorn or bulging areoles could not be observed. The cuticle of the male is only slightly better in preservation (Fig. 12L-O). Crowned areoles with short and longer apical filaments were observed, but the clusters of crowned areoles appear to be heterogeneous. In some clusters a central pair of crowned areoles is surrounded by circumcluster areoles (Fig. 12J), in other clusters the distinction between crowned areoles and circumcluster areoles is not easy to make and there appears to be a more gradual transition between these two types (Fig. 12K). Simple areoles appear to be covered with tiny knobs or spines (Fig. 12M, N). Further areolar types such as tubercle, thorn or bulging areoles were not observed. Therefore the determination of both specimens cannot go beyond the genus Chordodes.

\section{Chordodes brasiliensis Janda, 1893}

Material examined. V7351 (a) and (c-m) (10 males and 2 females). Fig. 12P-S, 13 A-F.

Location. Brazil, presumably Itapoá, Santa Catarina (see remarks from the catalogue).

Remarks from the catalogue. Collected by W. Ehrhardt on January 17, 1910. As location, the catalogue says "Humboldt-Geb. am Itapoeú", some letters are not clear. This location could not be retrieved, but Itapoá is close. Additionally, there are other catalogue entries with the same date and same collector having as location Joinville, which is close to Itapoá in the province Santa Catarina.

Occurs in publications. None

Remarks. The catalogue notes " $\mathrm{dv}$ ", meaning "diverse" as number of specimens. Thirteen specimens were found, one of them (b) is determined as Acutogordius cf. acuminatus (see there), the others are determined as Chordodes brasiliensis. The cuticle has numerous isolated, tall and slender crowned areoles (Fig. 12P-S, 13A, $\mathrm{B}$ ), which is typical for Chordodes brasiliensis (see De Villalobos et al. 2004, Schmidt-Rhaesa et al. 2008). One specimen (e) has areoles with very long apical filaments along a longitudinal line (Fig. 13C, D), presumably on the ventral side. Such crowned areoles with long filaments have been reported only from females (Camerano 1897, De Villalobos et al. 2004).

\section{Chordodes jandae Camerano, 1895 or C. skorikovi Camerano, 1903}

Material examined. V4064 (1 male and 1 female). Fig. $13 \mathrm{G}-\mathrm{J}$.

Location. Indonesia, Sumatra (as “O. Sumatra, Dali, Indrapura Estab").

Remarks from the catalogue. Collected by "Gebr. Siemssea" (no date given). Received by the museum on March 21, 1896. Determined as "Gordiiden".

Occurs in publications. unknown

Remarks. The simple areoles have the shape of blackberry areoles (Fig. 13I). Bulging, tubercle and thorn areoles are present (Fig. 13I). The crowned areole clusters are composed of approximately 12 areoles (Fig. 13J) and are therefore intermediate between the numbers given for $C$. jandae (20) and C. skorikovi (7-8) (see Schmidt-Rhaesa et al. 2008).

Chordodes janovyi Bolek, Schmidt-Rhaesa, Hanelt \& Richardson, 2010

Material examined. V13291 (1 male)

Location. Cameroon, Menoua river drainage in the village Bawa $\left(5^{\circ} 24^{\prime} \mathrm{N}, 10^{\circ} 03^{\prime} \mathrm{E}\right)$.

Remarks from the catalogue. Collected in June 2006. Occurs in publications. Bolek et al. (2010)

Remarks. Holotype of this species. See Bolek et al. (2010) for all information about this specimen.

Material examined. V13292

Same data as for V13291, paratype of this species. See Bolek et al. (2010) for all information about this specimen.

\section{Chordodes japonensis Inoue, 1951}

Material examined. V4599 (sex unknown because of damaged posterior end). Fig. 13K, L.

Location. "Japan, Schikoku, Tosa, Mano Bogawa, Kamigori"

Remarks from the catalogue. Collected by Lenz on July 27, 1897. Received by the museum on August 11, 1897. Determined as "Gordiide".

Occurs in publications. unknown

Remarks. The cuticle of the specimen is in most of the investigated part covered by the unstructured larval cuticle (Fig. 13L). In the parts where the adult cuticle can be observed (Fig. 13K, L) structures correspond to the descriptions given for Chordodes japonensis (see, e.g., Inoue 1952, Schmidt-Rhaesa 2004). 
Material examined. V13282 ( female).

Location. Japan, Campus of Nakamura Gakuen Sanyo High School, Imajukuaoki 1042-33, Nishi-ku, Fukuoka City, Fukuoka Prefecture, Kyushu (3333'58"N, 130¹7'22"E).

Remarks from the catalogue. Collected by Yuriko Kuribashi on October 12-18, 2008 from host Hierodula patellifera.

Occurs in publications. Schmidt-Rhaesa and Urabe (2009).

Remarks. This specimen is only briefly mentioned in Schmidt-Rhaesa and Urabe (2009) as a new record of location.

\section{Chordodes cf. japonensis}

Material examined. V5202 (1 male). Fig. 13M-P.

Location. Japan, Tokyo

Remarks from the catalogue. Collected by Jourdan (no date given). Received by the museum on February 14,1899 . Found in an undetermined mantid. Determined as "Gordius".

Occurs in publications. unknown

Remarks. The cuticle is not in very good shape, but it largely corresponds to the cuticular pattern of $C$. japonensis (compare specimen V4599 and Inoue 1952, Schmidt-Rhaesa 2004) (Fig. 13M-O).

\section{Chordodes cf. joyeuxi Dorier, 1935}

Material examined. V5778 (1 female). Fig. 14A-F.

Location. Indonesia, Sumatra, Lomgei Lalah, Indragiri

Remarks from the catalogue. Collected by W. Burchard (no date given). Received by the museum on $\mathrm{Au}-$ gust 26, 1901. Determined as "Gordius".

Occurs in publications. unknown

Remarks. The simple areoles have the shape of blackberry areoles (Fig. 14B, F), bulging areoles are absent. Thorn and tubercle areoles are present (Fig. 14B-E), thorn areoles are quite large (Fig. 14B, C). Crowned areoles with short apical filaments and those with long filaments both occur (Fig. 14B, D, F). According to the key from Schmidt-Rhaesa et al. (2008) the specimens closely resembles $C$. joyeuxi from Vietnam.

\section{Chordodes parabipilus Kintsurashvili, Schmidt-Rhae-} sa \& Gorgadze, 2011

Material examined. V13269 (1 female, holotype) Location. Georgia, village Tsitamuri, $20 \mathrm{~km}$ from Tbilisi. Remarks from the catalogue. Collected by Temur Gvalia on September 30, 2002, given by N. Kintsurashvili. Determined by Schmidt-Rhaesa in 2008.

Occurs in publications. Kintsurashvili et al. (2011)

Remarks. Holotype of this species. See Kintsurashvili et al. (2011) for all information about this specimen.
Chordodes polycoronatus Schmidt-Rhaesa \& Brune, 2008

Material examined. V11540 (1 male). Fig. 14G-I.

Location. Langcat, Sumatra, Indonesia.

Remarks from the catalogue. Collected by Ernst Versmann (date unknown). Received by the museum on March 9, 1931. Originally determined as "Gordiide".

Occurs in publications. unknown

Remarks. With the large clusters of crowned areoles (Fig. 14G, I) the specimen closely resembles C. polycoronatus, described by Schmidt-Rhaesa and Brune (2008) from Malaysia.

\section{Chordodes queenslandi Schmidt-Rhaesa, 2002}

Material examined. V2231 (1 female)

Location. Australia, Sidney.

Remarks from the catalogue. Collected by Dämel (no collection date or date when received by the museum given). Determined by Römer in 1893 as C. bouvieri, by Heinze in 1935 as C. modiglianii and by Schmidt-Rhaesa in 2002 as C. queenslandi.

Occurs in publications. Römer (1895, page 797), briefly in Römer (1896, page 283), Heinze (1935a, page 24), Schmidt-Rhaesa (2002b, page 1573).

Remarks. As explained in Schmidt-Rhaesa (2002b), this specimen corresponds to the (then) newly described species $C$. queenslandi and does not fit the descriptions of the other two species $C$. bouvieri and $C$. modiglianii.

\section{Chordodes jelkae sp. $\mathbf{n}$.}

http://zoobank.org/7962277E-8D0A-48C6-A164-A3818DB5FD00

Material examined. V10960 (2 females). Fig. 15A-F.

Location. Rwanda, Kabgayi, "Poste de Kigali”.

Holotype. Specimen 10960 (I).

Remarks from the catalogue. Collected by "Freres Rodrigues v.d. Weissen Vätern" (no collection date). Received by the museum on September 20, 1929.

Etymology. The species is named after and dedicated to my oldest daughter, Jelka.

Descsription. The two females measure 90 (I) and 85 (II) $\mathrm{mm}$ in length and $0.9 / 1.0 \mathrm{~mm}$ in diameter, respectively. The anterior end tapers towards the tip. The body colour is a dark brown general occurrence, with brown basic colour and darker patches (the "leopard pattern"). The anterior tip is white and blends into the brown body colour. Specimen (I) is well preserved, characters of specimen (II) are less well visible (Fig. 15F). The following description is therefore based on specimen (I), 
which is designated as the holotype. The cuticle shows the characteristic types of areoles known from other species of Chordodes. The simple areoles are roundish, often longer than broad (Fig. 15C, E). Their longer axis is perpendicular to the longitudinal axis of the animal. Simple areoles are closely together (Fig. 15C, E). On the apical side they have a tuft of short (about $3 \mu \mathrm{m}$ ) bristles (Fig. 15C-E), in some cases these fine bristles are dissolved and do not form a clear tuft. Among the simple areoles are occasional tubercle areoles, the tubercle is in some cases pointed (Fig. 15E). Thorn areoles were not observed. Crowned areole clusters are composed of two central crowned areoles with moderately long apical filaments $(<20 \mu \mathrm{m})$, which are surrounded by $10-12$ circumcluster areoles (Fig. 15C). The apical filaments of the crowned areoles originate laterally around a more or less flat apical surface of the areole, this surface is divided by several grooves into several compartments (Fig. 15C). The apical filaments may divide basally, but more distal divisions were not observed. The circumcluster areoles have a tuft of bristles on top (Fig. 15C). This tuft varies in its form, it either resembles the tuft of simple areoles as all bristles originate in the center of the apical surface or, in some circumcluster areoles, the apical surface is flat and the bristles extend laterally, comparable (though shorter) than in crowned areoles (Fig. 15C). Along one longitudinal line, probably the ventral midline, crowned areoles have very long apical filaments (approximately $170 \mu \mathrm{m})$ (Fig. 15B), in contrast to crowned areoles in the remaining parts of the body, which have shorter apical filaments (Fig. 15A).

Remarks. Species of Chordodes are quite similar in their cuticular structure. Species are distinguished by the presence or absence of particular types of areoles or when cuticular structures exhibit a particular substructure. Characteristic for this new species is the form of the simple areoles. In most species of Chordodes the simple areoles have either no bristles or scattered fine bristles on their apical surface. SEM investigations reveal that small bristles may be more abundant than known on the basis of traditional light microscopical investigation and they may even form small tuft-like structures as present, e.g. in $C$. parabipilus Kintsurashvili, Schmidt-Rhaesa \& Gorgadze, 2011 (Kintsurashvili et al. 2011), C. moutoni Camerano, 1895 (Schmidt-Rhaesa and Yadav 2013) and C. combiareolatus Schmidt-Rhaesa, Limatemjen \& Yadav, 2015 (Schmidt-Rhaesa et al. 2015). Compared to these species, the tuft of bristles is larger in C. jelkae sp. n. A distinct tuft of bristles is present in C. villalobi, a species from Malaysia (Schmidt-Rhaesa and Brune 2008), but this is more pronounced than in $C$. jelkae sp. n. . In combination to the shape of the tuft of bristles on the simple areoles, an important difference between all mentioned species and C. jelkae sp. n. is that thorn areoles are absent in C. jelkae sp. n., but present in all other species. Additinally, simple areoles are closer together in C. jelkae sp. n. than in C. villalobi. Characters in specimen 10960 (II) are not as well visible and its assignment to C. jelkae sp. n. is likely, but not certain.

\section{Genus Gordionus Müller, 1926}

The genus Gordionus is characterized by the following character combination: one type of areoles present on the cuticle, male posterior end with bristles anterolateral of the cloacal opening and spines posterior of the cloacal opening and directly around it. Currently, 56 species are included in this genus (Schmidt-Rhaesa 2013), but it is currently not well understood, whether these species are real, because the amount of character variation is not clear. There is a broad range of minute cuticular differences between Gordionus specimens and it was suspected that such a range reflects intraspecific variability. This was for example made probable for the species $G$. violaceus and $G$. wolterstorffii, which, although having quite dissimilar cuticular patterns, are connected by a range intermediate cuticular patterns (Schmidt-Rhaesa 2001). Unpublished molecular results (COI-gene) support that there are two species, one ( $G$. violaceus) with one typical cuticular pattern and another (G. wolterstorffii) with a variable cuticular pattern. This would mean that some species descriptions (see, e.g., Heinze 1941) fall into the range of cuticular variation of $G$. wolterstorffii. This does, for example, account to G. scaber, of which some specimens in the collection have been determined. Because the mentioned molecular results have not been published yet, I decide here to retain the determination as G. scaber, when specimens correspond to the character description as given by Müller (1926) and Heinze (1937, 1941).

\section{Gordionus sp.}

Material examined. V2215 (3 females and one specimen without posterior end). Fig. 9E.

Location. "East Africa, middle Ussuri” (as "Ostafrika, mittlerer Ussuri”) [a river Ussuri could not be located].

Remarks from the catalogue. Collected by "Fischer" (no collection date or date when received by the museum given). Carabus smaragdinus is given as host. Determined by Römer in 1895 and Heinze in 1935 as male of Gordius aquaticus.

Occurs in publications. Römer (1895, page 793), briefly in Römer (1896, page 260).

Remarks. Presently, the vial contains four specimens: three females, of which one was investigated here by SEM and one specimen in an extra vial, this specimen is lacking the posterior end. According to the catalogue the number of specimens should be 2 and the determination says "Gordius aquaticus సै". Römer (1895) mentions 2 males and 4 females from this locality and this host, therefore it remains unknown, how many specimens were included in this vial originally. The potential host is the beetle Carabus smaragdinus. It is not mentioned, whether all specimens originate from the one host and the host 
is not included in the vial. Additionally, the beetle was probably not determined correctly, as C. smaragdinus is not an African species (according to Wikipedia). The cuticle contains polygonal areoles (Fig. 9E) that are clearly separated from each other and therefore it is most likely that this specimen belongs to the genus Gordionus.

Material examined. V2217 (according to catalogue 3 males, only 1 male found in vial). Fig. 9F-H.

Location. Germany (not further specified), from carabid beetle.

Remarks from the catalogue. Collected by "v. Siebold" (no collection date or date when received by the museum given). Determined by Von Siebold as Gordius subbifurcatus, by Römer in 1893 as Gordius tolosanus. Genus corrected to Parachordodes by Heinze in 1935 (according to additional label in vial). Additional remark: type material of Gordius subbifurcatus.

Occurs in publications. Römer (1895, page 794).

Remarks. Gordius subbifurcus Von Siebold, 1848 (not subbifurcatus as in catalogue!) is synonymous to Parachordodes tolosanus (Dujardin, 1842) (see, e.g., Heinze 1941). Von Siebold (1848) did not really describe this species, but writes about a horsehair worm emerging from Molops elatus: "it possesses a slight longitudinal furrow at the posterior end, therefore I will call it ... Gordius subbifurcus". According to the catalogue, the worm(s) of number V2217 are the type material of Gordius subbifurcus, but I regard this as not likely. First, neither in the vial, nor in the catalogue, it is marked as type material. Second, according to the catalogue, Von Siebold collected the material himself from an undetermined carabid beetle. In Von Siebold's 1848 publication he mentions G. subbifurcus twice, first from Molops elatus sent by Prof. Fuchs and second from Calathus cisteloides from the helminthological collection in Freiburg. Both these reports do not correspond to the data given in the Hamburg catalogue.

Finally, the determination as Parachordodes tolosanus could not be supported here. The genus Parachordodes has two types of areoles, one of which are the so-called superareoles (see, e.g., Schmidt-Rhaesa 2013). The SEM investigation showed only one type of areoles (Fig. 9F), therefore this specimen likely belongs to the genus Gordionus. The posterior end shows a row of precloacal bristles that is continuous anterior of the cloacal opening and not divided into two lateral rows. This single character has been taken to name a new genus, Semigordionus (Heinze 1952), with one species from Austria. Zanca and Schmidt-Rhaesa (2006) found it more appropriate to regard Semigordionus as a member of the genus Gordionus, but did not formalize this step, because further investigations of the posterior end of $S$. circumannulatus should be awaited.

Material examined. V2236(II) (1 female) One specimen is indicated in the catalogue, but 2 specimens are present. The second specimen (I) is determined as Parachordodes tolosanus. Fig. 9I.
Location. Germany, Göttingen.

Remarks from the catalogue. Collected by Schlotthauber (no collection date or date when received by the museum given). Determined by Schlotthauber in 1854 as Gordius aquaticus, corrected by Heinze in 1935 to Parachordodes tolosanus. Host: Harpalus ruficornis crossed out and replaced by Ophonus cephalotes.

Occurs in publications (as P. tolosanus). Heinze (1937, page 285), Heinze (1941, page 24).

Remarks. Only one type of areoles is present (Fig. 9I), no superareoles could be found. Therefore the specimen is determined as Gordionus sp. As the catalogue indicates only one specimen, it is unknown whether this second specimen does belong to the vial originally. If it does, it is unknown whether both specimens emerged from the beetle.

Material examined. V9615 ( 2 females) (3 specimens are indicated in the catalogue). Fig. 9J, K.

Location. Macedonia, stream to river Vardar, close to Veles (as "Bach zum Vardoe, N. v. Veles")

Remarks from the catalogue. collected by F. Ahlborn in 1916 (date not given). Received by the museum on November 22, 1923. Originally determined as "Gordius".

Occurs in publications. unknown

Remarks. The cuticle of both specimens has roundish areoles surrounded by a broad and flat interareolar space, in which interareolar bristles are present (Fig. 9J, K). This somewhat resembles $G$. violaceus, but in that species the interareolar furrows are not so broad. Specimens V9615 cannot be assigned to a species of Gordionus with certainty.

Material examined. V11117 (1 male). Fig. 9L-O.

Location. Germany, ditch in Lokstedt, Hamburg.

Remarks from the catalogue. Collected by H. Richter (date unknown). Received by the museum on July 25 , 1930. Determined by Heinze in 1935 as Gordionus scaber.

Occurs in publications. Heinze (1937, page 309), Heinze (1941, page 32)

Remarks. The areoles on the cuticle of this specimen are not clearly recognizable and appear to be artificially altered (Fig. 9L). Therefore an exact determination cannot be given. The posterior end (Fig. 9M-O) contains, as far as could be observed, mainly unbranched precloacal (Fig. 9N) and circumcloacal (Fig. 9O) bristles.

Material examined. V12470 (1 male). Fig. 10A.

Location. Germany, Friedrichstadt an der Eider.

Remarks from the catalogue. collected by Niggemeyer (no date given). Received by the museum on May 16, 1936. Determined by Thiel in 1936 as Gordius aquaticus.

Occurs in publications. unknown

Remarks. The posterior end of this specimen is unfortunately lost during preparation for SEM, but notes taken before the loss indicate that a postcloacal crescent is absent. The cuticle has one type of areoles (Fig. 10A), it is possible that this specimen belongs to G. violaceus, but preservation is not good enough for a certain determination. 
Material examined. V13313 (1 male)

Location. Japan, Hirakura, Higaashim.

Remarks from the catalogue. Collected by Takuya Sato on September 12, 2008. Received by the museum in 2011 .

Occurs in publications. Sato et al. (2012)

Remarks. Specimen is a voucher for a phylogenetic analysis in Sato et al. (2012).

Material examined. V13316 (1 male)

Location. Japan, Hirakura, Nishimata.

Remarks from the catalogue. Collected by Takuya Sato on September 29, 2008. Received by the museum in 2011.

Occurs in publications. Sato et al. (2012)

Remarks. Specimen is a voucher for a phylogenetic analysis in Sato et al. (2012).

\section{Material examined. V13319 (1 male)}

Location. Japan, Kumano, Misen.

Remarks from the catalogue. Collected by Takuya Sato on September 14, 2009. Received by the museum in 2011 .

Occurs in publications. Sato et al. (2012)

Remarks. Specimen is a voucher for a phylogenetic analysis in Sato et al. (2012).

Material examined. V13320 (1 male)

Location. Japan, Hirakura, Nishimata.

Remarks from the catalogue. Collected by Takuya Sato on September 14, 2009. Received by the museum in 2011.

Occurs in publications. Sato et al. (2012)

Remarks. Specimen is a voucher for a phylogenetic analysis in Sato et al. (2012).

Material examined. V13361 (1 female; transferred from V2220). Fig. 10B

Location. Germany, Göttingen, Hainholz, in source.

Remarks from the catalogue. Collected by Schlotthauber (no collection date or date when received by the museum given). Determined by Römer in 1893 as Gordius violaceus, corrected by Heinze in 1935 to Parachordodes tolosanus.

Occurs in publications. Römer (1895, page 794, as $G$. violaceus), probably Heinze, only as "Göttingen" (1937, page 283 ; 1941, page 26 , as $P$. tolosanus).

Remarks. SEM reinvestigation showed that the female does not have superareoles as required for the original determination as $P$. tolosanus. Because it has only one type of areoles (Fig. 10B), it is designed as Gordionus $\mathrm{sp}$. The specimen was formerly included in a lot of five worms under the number V2220.

Material examined. V13362 (1 male; transferred from V2225). Fig. 10C.

Location. Germany, Hamburg, river Bille.

Remarks from the catalogue. Collected by Steinblinck (no date given), received by the museum on January
1, 1895. Determined by Römer in 1893 as Gordius violaceus, corrected to Gordionus meissneri by Heinze in 1935.

Occurs in publications. Römer (1895, page 794), briefly in Heinze (1937, page 302), Heinze (1941, page 45).

Remarks. SEM reinvestigation shows partly fused areoles (Fig. 10C), consistent with patterns found in the character range of $G$. wolterstorffii (see Schmidt-Rhaesa 2001). Gordionus meissneri, to which the specimen was originally assigned, has isolated areoles that are not fused to short rows as in V13362 (see, e.g., Heinze 1941). The specimen was formerly included in a lot with another male worms (determined as G. violaceus) under the number V2225.

\section{Gordionus bageli Schmidt-Rhaesa \& Gusich, 2010}

Material examined. V13278 (1 male)

Location. Switzerland, Röserental near Liestal, Tafeljura. In Thuja forest.

Remarks from the catalogue. Collected by Valeria Viktoria Gusich in 2008.

Occurs in publications. Schmidt-Rhaesa and Gusich (2010)

Remarks. Holotype for this species. See Schmidt-Rhaesa and Gusich (2010) for all information about this specimen.

\section{Gordionus barbatus Schmidt-Rhaesa \& Cieslak, 2008}

Material examined. V13259 (1 male)

Location. Spain, Lleida, Llesp, Barranc Basculina $\left(42^{\circ} 27^{\prime} 24.5^{\prime \prime} \mathrm{N}, 0^{\circ} 44^{\prime} 57^{\prime \prime} \mathrm{W}\right)$.

Remarks from the catalogue. Collected by J. Fresneda, I. Ribera and A. Cieslak on August 2, 2006. Received by the museum on July 3, 2008

Occurs in publications. Schmidt-Rhaesa and Cieslak (2008)

Remarks. Holotype of this species. See Schmidt-Rhaesa and Cieslak (2008) for all information about this specimen.

\section{Gordionus chinensis (Villot, 1874)}

Material examined. V13250 (1 male)

Location. Japan, Yumitehara river, Totsu river system, Kii Peninsula.

Remarks from the catalogue. Collected by Takuya Sato in 2007. Received by the museum on May 20, 2008.

Occurs in publications. Schmidt-Rhaesa and Sato (2009)

Remarks. see Schmidt-Rhaesa and Sato (2009) for all information about this specimen.

Material examined. V13251 (1 male)

Same data as V13250, see there. 
Material examined. V13312 (1 male)

Location. Japan, Arida, Ninomata.

Remarks from the catalogue. Collected by Takuya Sato on September 13, 2008. Received by the museum in 2011.

Occurs in publications. Sato et al. (2012)

Remarks. Specimen is a voucher for a phylogenetic analysis in Sato et al. (2012).

Material examined. V13314 (1 male)

Location. Japan, Hirakura, Higaashim.

Remarks from the catalogue. Collected by Takuya Sato on September 12, 2008. Received by the museum in 2011.

Occurs in publications. Sato et al. (2012)

Remarks. Specimen is a voucher for a phylogenetic analysis in Sato et al. (2012).

\section{Material examined. V13315 (1 male)}

Location. Japan, Miyagawa, Muzutani.

Remarks from the catalogue. Collected by Takuya Sato on September 29, 2008. Received by the museum in 2011.

Occurs in publications. Sato et al. (2012)

Remarks. Specimen is a voucher for a phylogenetic analysis in Sato et al. (2012).

Material examined. V13317 (1 male)

Location. Japan, Kumano, Sankou.

Remarks from the catalogue. Collected by Takuya Sato on October 13, 2010. Received by the museum in 2011.

Occurs in publications. Sato et al. (2012)

Remarks. Specimen is a voucher for a phylogenetic analysis in Sato et al. (2012).

\section{Material examined. V13318 (1 male)}

Location. Japan, Kumano, Sankou.

Remarks from the catalogue. Collected by Takuya Sato on October 13, 2010. Received by the museum in 2011.

Occurs in publications. Sato et al. (2012)

Remarks. Specimen is a voucher for a phylogenetic analysis in Sato et al. (2012).

Material examined. V13321 (1 male)

Location. Japan, Kumano, Sankou.

Remarks from the catalogue. Collected by Takuya Sato on October 13, 2010. Received by the museum in 2011.

Occurs in publications. Sato et al. (2012)

Remarks. Specimen is a voucher for a phylogenetic analysis in Sato et al. (2012).

\section{Gordionus kii Schmidt-Rhaesa \& Sato, 2009}

Material examined. V13252 (1 male)

Location. Japan, Yumitehara river, Totsu river system, Kii Peninsula.

Remarks from the catalogue. Collected by Takuya Sato in 2007. Received by the museum on May 20, 2008.
Occurs in publications. Schmidt-Rhaesa and Sato (2009).

Remarks. Holotype for this species. See Schmidt-Rhaesa and Sato (2009) for all information about this specimen.

\section{Gordionus scaber Müller, 1926}

Material examined. V2221 (1 male). Fig. 10D, E.

Location. Germany, Hamburg, Bergedorf.

Remarks from the catalogue. Collected by Thalenhorst (no collection date or date when received by the museum given). Determined by Römer in 1893 as Gordius violaceus and by Heinze in 1935 as Gordionus scaber (s. str.).

Occurs in publications. Römer (1895, page 794), briefly in Heinze (1937, page 309), Heinze (1941, page 32).

Remarks. Although not optimally preserved, it is evident that the areoles are isolated or partly fused in short rows (Fig. 10D), which corresponds to the description of Gordionus scaber scaber (see, e.g., Heinze 1941).

Material examined. V10924 (1 male). Fig. 10F-H.

Location. Germany, Medingen, Bad Bevensen, presumably stream Wohbeck (as "aus dem Wohbach", "Wohbeck is the current name).

Remarks from the catalogue. Collected by F. Richter (date not given). Received by the museum on June 29, 1929. Determined by Heinze in 1935 as Gordionus scaber.

Occurs in publications. Heinze (1937, page 309), Heinze (1941, page 32).

Remarks. The cuticle shows roundish areoles with an individual character, but which are partly fused with neighbouring areoles in longitudinal direction (not figured). This is consistent with the pattern described for Gordionus scaber (e.g., Heinze 1941). The posterior end has, as far as can be observed, unbranched precloacal bristles (Fig. 10F, H), but these are covered with some dirt and a potential fine branching, as is described by, e.g., Heinze (1941) for G. scaber, could not be excluded with certainty. Therefore, Heinze's determination as G. scaber is confirmed here with the additional remark that this may fall into the range of characters for a polymorphic species G. wolterstorffii.

Gordionus turkensis Schmidt-Rhaesa \& Cieslak, 2008

Material examined. V13262 (1 male)

Location. Turkey, Karabük Rd. E80, E cross to Gerede, stream in Cayorenguney $\left(40^{\circ} 48^{\prime} 23^{\prime} \mathrm{N}, 32^{\circ} 16^{\prime} .5^{\prime \prime} \mathrm{E}\right), 1231 \mathrm{~m}$.

Remarks from the catalogue. Collected by I. Ribera on April 28, 2006. Received by the museum on July 3, 2008.

Occurs in publications. Schmidt-Rhaesa and Cieslak (2008).

Remarks. Holotype of this species. See Schmidt-Rhaesa and Cieslak (2008) for all information about this specimen. 


\section{Gordionus violaceus (Baird, 1853)}

Material examined. V2225 (originally 2 males, 1 male is regarded as Gordionus sp. and transferred to a new catalogue number 13362). Fig. 10I, J.

Location. Germany, Hamburg, river Bille.

Remarks from the catalogue. Collected by Steinblinck (no date given). Received by the museum on January 25, 1895. Determined by Römer in 1893 as Gordius violaceus, corrected to Gordionus meissneri by Heinze in 1935.

Occurs in publications. Römer (1895, page 794), briefly in Heinze (1937, page 302), Heinze (1941, page 45).

Remarks. SEM reinvestigation shows one type of areoles surrounded by interareolar bristles (Fig. 10I), therefore the determination as $G$. violaceus is supported.

Material examined. V11455 (2 females). Fig. 10K, L.

Location. Germany, Rügen.

Remarks from the catalogue. Collected by A. Thienemann (date unknown). Received by the museum on November 12, 1930. Originally determined by A. Thienemann as Parachordodes tolosanus. Corrected by Heinze in 1935 to Gordionus violaceus.

Occurs in publications. unknown. Heinze (1937, 1941) mentions Rügen as location for G. violaceus, but with addition "Stubbnitz", which is not given in the catalogue. Therefore this may be a different specimen.

Remarks. In both females the cuticle has round areoles completely surrounded by interareolar bristles (Fig. $10 \mathrm{~K}, \mathrm{~L}$ ), which is characteristic for G. violaceus (compare, e.g., Schmidt-Rhaesa 2001).

\section{Gordionus wolterstorffii (Camerano, 1888)}

Material examined. V2218 (2 males, 1 female according to catalogue, presently only 1 male in vial). Fig. 11A.

Location. Germany, Göttingen, Hainholz, in source.

Remarks from the catalogue. Collected by Schlotthauber (no collection date or date when received by the museum given). Determined by Römer in 1893 as Gordius tolosanus, corrected to Gordionus scaber scaber by Heinze in 1935.

Occurs in publications. Römer (1895, page 794), briefly in Römer (1896, page 262), Heinze (1937, page 309), Heinze (1941, page 32).

Remarks. Collector and collection dates are similar to V2220 determined as Parachordodes tolosanus. The cuticle shows irregular rows of fused areoles (Fig. 11A). According to Heinze (1941) Gordius scaber scaber has isolated areoles or areoles are fused to short rows, but the individual character of areoles remains visible. Such description does not correspond to the pattern observed in specimen V2218 by SEM. The long fused rows of areoles correspond to the description given for Gordionus scaber lineatus (e.g., in Heinze 1941), but also correspond to the description of G. wolterstorffii (Camerano, 1888) (see, e.g., Schmidt-Rhaesa 2001).
Material examined. V2222 (in the catalogue 5 males and 2 females are indicated, presently only 1 male is present). Fig. 11B, D.

Location. Germany, Kissingen (additional remark "Poppenhausen" in Römer 1895), in a fountain in field.

Remarks from the catalogue. Collected by Dömling (no date given). Received by the museum on September 23, 1893. Determined by Römer in 1893 as Gordius violaceus and by Heinze in 1935 as Gordionus scaber.

Occurs in publications. Römer (1895, page 794), briefly in Heinze (1937, page 309), Heinze (1941, page 32).

Remarks. The cuticle shows irregular rows of fused areoles (Fig. 11B). As described above (V2218), this is characteristic for $G$. wolterstorffii rather than for G. scaber.

Material examined. V5255 (1 male). Fig. 11C, E.

Location. Germany, Hamburg, Elbe river.

Remarks from the catalogue. Collected by Wiebelitz (no date given). Received by the museum on June 14, 1899. Determined by Heinze in 1935 as Gordionus scaber.

Occurs in publications. unknown

Remarks. The cuticle shows irregular rows of fused areoles (Fig. 11C). As described above (V2218), this is characteristic for $G$. wolterstorffii rather than for G. scaber.

\section{Genus Gordius Linné, 1758}

Species of the genus Gordius are not easy to determine due to their scarceness of diagnostic characters, especially in female worms. Additionally, the range of intraspecific variation for several characters is not known (Schmidt-Rhaesa 2010). Finally, fine structural characters such as the presence and distribution of fine bristles have been observed only with SEM, but are not reported in older species descriptions (see Schmidt-Rhaesa 2010).

Characteristic for the genus is the presence of a semicircular or parabolic cuticular fold posterior of the ventral cloacal opening, which is called the postcloacal crescent. Posterior of this structure, the body is divided into paired lateral tail lobes. In Gordius, the tail lobes are rounded, in contrast to the genus Acutogordius, which has pointed tail lobes and is the only other genus with a postcloacal crescent (see below). In females, there is no difference to females of other genera, therefore females are more difficult to assign. The body cuticle in Gordius specimens can be either smooth or ornamented with roundish or polygonal structures called areoles. Areoles are present in other genera, too, especially in Gordionus. A smooth cuticle is only present in Gordius, but it has been described from several species (15 European species according to Schmidt-Rhaesa 2010). Therefore, a smooth cuticle indicates that the specimen belongs to Gordius, but it is not indicative for a certain species. Most species can only be determined with the help of certain structures, mostly bristles, on the male posterior end. In worn or dirty specimens such characters may not be visible, therefore determination requires some caution. This is the reason that in this reinvestigation a number of determinations to species level are changed to Gordius sp. 


\section{Gordius sp.}

Material examined. V 2207 (1 male). Fig. 1A.

Location. Germany, Kellersee, Holstein.

Remarks from the catalogue. Collected by "v. Pöppinghausen" (no date given), received by the museum on August 10, 1894. Determined as G. aquaticus by Römer in 1893 and as G. mülleri by Heinze in 1935.

Occurs in publications. Römer (1895, page 791), Heinze (1937, page 320), Heinze (1941, page 59) (both Heinze's records with “?”).

Remarks. In Gordius muelleri Heinze, 1933 (writing in catalogue mülleri) there is some distance between the postcloacal crescent and the beginning of the bifurcation of the tail lobes (see Heinze 1933, 1937, 1941). As in the present specimen the postcloacal crescent is directly at the point of bifurcation (Fig. 1A), the determination as $G$. muelleri cannot be confirmed.

Material examined. V 2208 (3 specimens, 1 male was reinvestigated here). Fig. $1 \mathrm{~B}, \mathrm{C}$.

Location. Germany, Plön, Holstein.

Remarks from the catalogue. Collected by "Dr. G. Duncker" (no date given), received by the museum on January 18, 1894. Determined as G. aquaticus by Römer in 1893 and as G. albopunctatus by Heinze in 1935 .

Occurs in publications. Römer (1895, page 791), probably Heinze (1937, page 57), Heinze (1941, page 319) [several specific locations around Plön are listed].

Remarks. The cuticle is, in the investigated part, covered with material of unknown nature (Fig. 1C). The polygonal areoles, characteristic for G. albopunctatus (see, e.g. Schmidt-Rhaesa and Kristensen 2006) could not be observed and, therefore, the specimens are regarded here as Gordius sp.

Material examined. V2214 (1 female). Fig. 1D.

Location. Chile

Remarks from the catalogue. No detailed collecting locality in Chile mentioned, collector unknown. No collection date given and no date when received by the museum. Determined by Römer in 1893 as G. aquaticus, confirmed by Heinze in 1935.

Occurs in publications. Römer (1895, page 792), briefly in Römer (1896, page 260).

Remarks. Female worm with smooth cuticle (Fig. 1D), which occurs only in some species of Gordius. As Gordius aquaticus is restricted to the Palaearctic, hence this is probably another species of Gordius, such as G. robustus, but this cannot be determined with a female specimen.

Material examined. V2216 (1 female). Fig. 1E.

Location. Chile, Valdivia river.

Remarks from the catalogue. In catalogue: "Coll. Mich. 33", on record card "Michaelsen". No further collection date or date when received by the museum given. Determined by Römer in 1893 as Gordius aquaticus, also mentioned "Heinze 1935".
Occurs in publications. Römer (1895, page 793), briefly in Römer (1896, page 260).

Remarks. Female worm with smooth cuticle (Fig. 1E), see discussion under V2214.

Material examined. V2223 (in the catalogue 1 male and 1 female are mentioned, currently two fragments are present, from which at least one is from the male). Fig. 1F, G.

Location. Germany, Hamburg (no further details).

Remarks from the catalogue. Collector unknown, no date given. Date when received by the museum not given. Determined by Römer in 1893 as Gordius violaceus and by Heinze in 1935 as Gordius mülleri.

Occurs in publications. Römer (1895, page 794), briefly in Heinze (1937, page 320), Heinze (1941, page 59).

Remarks. The SEM reinvestigation shows a slight pattern of areoles on the cuticle (Fig. 1F). The cloacal opening, which should be oval in G. muelleri (see, e.g., Heinze 1941) is covered and not visible (Fig. 1G). The tail lobes of specimen V2223 are about twice as long as they are broad and not as short as they should be in $G$. muelleri (see, e.g., Heinze 1941). Therefore, the determination as $G$. muelleri is regarded as questionable.

Material examined. V2227 (1 female). Fig. 1H.

Location. "Viti Islands" (probably Viti Levu, Fiji-Islands).

Remarks from the catalogue. Collected or donated by "M.G.". No collection date or date when received by the museum given. Host: Phybalosoma pythonis (Phasmatodea). Determined by Römer in 1893 as Gordius aeneus, determination checked and confirmed by Heinze in 1935 .

Occurs in publications. Römer (1895, page 794), Römer (1896, page 268).

Remarks. Gordius aeneus is regarded an invalid species name (Schmidt-Rhaesa 2013). SEM investigation of specimen V2227 shows a smooth cuticular surface (Fig. $1 \mathrm{H})$, therefore an assignment to the genus Gordius is certain, but a concrete species cannot be determined.

Material examined. V2228 (1 female). Fig. 2A.

Location. unknown ("?" in catalogue).

Remarks from the catalogue. Collector unknown. No collection date or date when received by the museum given. Determined by Römer in 1893 as Gordius fulgur, determination confirmed by Heinze in 1935.

Occurs in publications. Römer (1895, page 795), briefly in Römer (1896, page 267).

Remarks. SEM investigation of specimen V2228 shows a smooth cuticular surface (Fig. 2A), therefore an assignment to the genus Gordius is certain, but a concrete species cannot be determined. Therefore, the original determination as G. fulgur was changed to Gordius sp.

Material examined. V2238 (1 specimen of unknown sex). Fig. 2B.

Location. Tanzania, Bagamoyo.

Remarks from the catalogue. Collected by Stuhlmann. No collection date or date when received by the museum given. Determined first as Gordius aquaticus, 
but "aquaticus" was later crossed out. No name of reviser is given. Worm found in an undetermined cricket.

Occurs in publications. unknown

Remarks. The worm is still inside the cricket, some loops of it are visible through an injury in the anterior part of the abdomen. Body ends were not removed, and a sex determination is therefore not possible. A piece of worm was removed from the outermost loop. The cuticle is smooth (Fig. 2B), therefore it is likely that this is a Gordius specimen.

Material examined. V2977 (1 female). Fig. 2C.

Location. Japan, Lake Candidius.

Remarks from the catalogue. Collected by H. Sauter (no date given), received by the museum on April 22, 1908. Originally determined as "Chordodes".

Occurs in publications. unknown

Remarks. SEM investigation reveals a smooth cuticle (Fig. 2C), therefore the specimen belongs to the genus Gordius.

Material examined. V3314 (1 female). Fig. 2D.

Location. "Elsass, Tannenberg bei Saales, 640m, in einer Heuschrecke". Revised location: France, Saales. Tannenberg is probably a sanatorium close to Saales.

Remarks from the catalogue. Collected by Dr. Alb. Graser (no date given), received by the museum on July 12, 1909. Host: a cricket.

Occurs in publications. unknown.

Remarks. The cuticle is smooth, but contains small keel-like structures perpendicular to the longitudinal body axis (Fig. 2D). These structures are unknown from species of Gordius.

Material examined. V4413 (1 male). Fig. 2E, F.

Location. Germany, "Bergedorf" close to Hamburg.

Remarks from the catalogue. Collected by "W. Fischer" (date not given). Received by the museum on October 1, 1896, determined as "Gordiide".

Occurs in publications. unknown

Remarks. The cuticle contains shallow areoles with polygonal or irregular outline (Fig. 2E). The postcloacal crescent borders the point of bifurcation of the two tail lobes, it is short and semicircular and extends slightly onto the tail lobes (Fig. 2F). Most of these characters fit to the description of $G$. undulatus as given by Heinze (1937), with the exception that in this species, there is a distance between the postcloacal crescent and the point of bifurcation of the tail lobes. With the exception of $G$. digitatus, which has strongly interdigitating areoles (see Schmidt-Rhaesa 2010), G. undulatus is the only species with areoles of an irregular shape. Therefore a definitive determination can currently not be given.

Material examined. V4598 (sex unknown, because posterior end is missing). Fig. $2 \mathrm{G}$.

Location. Japan, Schikoku, Mano bogawa, Kamigore, Tosa.

Remarks from the catalogue. Collected by Lenz on July 27, 1897. Received by the museum on August 11, 1897. Originally determined as "Gordiide".
Occurs in publications. unknown

Remarks. The specimen has a smooth cuticle (Fig. $2 \mathrm{G})$, but because the posterior end is missing, no further determination can be given.

Material examined. V4611 (1 male, 1 female). Fig. $2 \mathrm{H}-\mathrm{K}$.

Location. Italy, South Tyrol ("Süd-Tirol").

Remarks from the catalogue. Collected by Timm (no date given), received by the museum on August 21, 1897. Determined as "Gordius".

Occurs in publications. unknown

Remarks. Both specimens differ in their cuticular structure, which may indicate that they belong to different species. The female has a smooth cuticle (not figured), while the cuticle of the male has elongate areoles that are partly confluent with neighbouring ones and that are arranged perpendicular to the longitudinal body axis (Fig. 2H, I). This cuticular structure does match best, though not exactly, the description for G. tirolensis Heinze, 1937, a species described from Austria (Susalitsch, Kärnten) and also from South Tyrol (Brixen) (Heinze 1937, 1941). The posterior end contains a large postcloacal crescent that has a short distance to the cloacal opening and extends well onto the comparably long tail lobes (length to width slightly $>2: 1$ ) (Fig. $2 \mathrm{~J})$. The postcloacal crescent is angled. Around the cloacal opening, bordered posteriorly by the postcloacal crescent, there is a depressed area that is bordered by a fringed rim (Fig. 2K). The exact nature of this structure could not be detected, but it does not seem to be a row of bristles as is present in some (non-European) species such as $G$. paranensis (see below and Schmidt-Rhaesa et al. 2000) or G. attoni (see, e.g., Schmidt-Rhaesa et al. 2003). The description of the posterior end does not fit G. tirolensis (Heinze 1937, 1941) and therefore V4611 is treated here as Gordius sp.

Material examined. V4981 (1 male). Fig. 3A, B.

Location. Germany, Hamburg, Flottbeck, in drainage tubes.

Remarks from the catalogue. Collected by Ansorge (no date given), received by the museum on November 19, 1897. Determined by Heinze in 1935 as G. aquaticus.

Occurs in publications. Heinze (1937, page 331) and Heinze (1941, page 70). In both cases, Heinze adds the date "19.11.97", the date when received by the museum.

Remarks. The SEM reinvestigation shows a smooth cuticle (Fig. 3A) and some short bristles on the inner side of the tail lobes (Fig. 3B, C). As it is not clear whether such bristles are present in G. aquaticus (compare Schmidt-Rhaesa 2010), the specimen is referred to here as Gordius sp.

Material examined. V5046 (1 female). Fig. 3D.

Location. Switzerland, "Axenstr. bei Tells Platte" (probably close to Sisikon, Uri, Swizerland).

Remarks from the catalogue. Collected by "Michaelsen 20.VI.98", received by the museum on June 30, 1898. Determined as "Gordius". Found in man ("im Menschen").

Occurs in publications. unknown 
Remarks. The cuticle is smooth, but has some fungus-like covering (Fig. 3D), the determination is not possible with certainty.

Material examined. V5459 (1 male). Fig. 3E, F.

Location. Germany, Hamburg, river Elbe ("Elbe bei Hamburg").

Remarks from the catalogue. Collected by A. Westphalen (no date given). Received by the museum on April 26, 1900. Determined by Heinze in 1935 as Gordius mülleri.

Occurs in publications. Heinze (1937, page 320), Heinze (1941, page 59)

Remarks. The cuticle does not contain areoles (Fig. $3 \mathrm{E})$. The posterior end is in bad shape, the postcloacal crescent is directly at the point of bifurcation of the tail lobes (Fig. 3F). As explained for specimen V2207, this argues against a determination as $G$. muelleri.

Material examined. V5523 (1 female). Fig. 3G.

Location. Germany, Rahlstedt ("Alt-Rahlstedt"), under a flower pot.

Remarks from the catalogue. Collected by Ilse Schultze (date not given). Received by the museum on September 15, 1900. Determined by Heinze in 1935/36 as "Gordius? aquaticus".

Occurs in publications. Heinze (1937, page 331), Heinze (1941, page 70).

Remarks. The cuticle of this specimen is smooth (Fig. $3 \mathrm{G})$, therefore no further determination can be given.

Material examined. V5773 (1 male). Fig. 3H, I.

Location. Germany, Eppendorfer Mühlenteich, Hamburg.

Remarks from the catalogue. Collected by "Lehrer" (teacher ?) Wagner (date unknown). Received by the museum on July 2, 1901. Determined by Heinze in 1935 as Gordius mülleri (= muelleri).

Occurs in publications. Heinze (1937, page 320), Heinze (1941, page 59).

Remarks. The body cuticle is heavily covered with some artificial crust (Fig. $3 \mathrm{H}$ ), therefore it could not be determined with certainty, whether areoles are present or not. The posterior end is clearer, but does not correspond to the descriptions given for G. muelleri (e.g. in Heinze 1941), because the postcloacal crescent is directly on the point of bifurcation of the tail lobes in V5773 (Fig. 3I) and not, as in G. muelleri, in some distance from it.

Material examined. V6341 (1 female). Fig. 3J.

Location. Germany, Hessen, Stream Olbe.

Remarks from the catalogue. Collected by G. Ulmer in July 1900. Received November 14, 1903. Determined by Heinze in 1935 as Gordius stellatus.

Occurs in publications. Heinze (1941, page 71) (not in Heinze 1937)

Remarks. The cuticle is smooth with some irregularly placed shallow elevations (Fig. 3J). Star-like structures on the cuticle as described for G. stellatus are likely artificial (Heinze 1937) and it is not clear whether this species is valid or not (e.g. Schmidt-Rhaesa 1997). This reinvestigation cannot assign the specimen to any species of Gordius with certainty.

Material examined. V6488 (1 male). Fig. 3K-M.

Location. Germany, Hannover, River Örtze.

Remarks from the catalogue. Collected by Th. Lindemann (no date given). Received by the museum on July 28, 1904. Determined by Michaelsen in 1904 as Gordius aquaticus and by Heinze in 1935 as Gordius setiger.

Occurs in publications. Heinze (1937, page 316), Heinze (1941, page 58)

Remarks. The cuticle has very indistinct elevations that might represent areoles (Fig. 3K). The entire cuticle has a fine striation (Fig. 3L). The posterior end has some fine bristles on the inner side of the tail lobes. The postcloacal crescent is narrow and semicircular, it extends onto the tail lobes (Fig. 3M). The current characters do not fit to a certain species of Gordius, but are regarded not significant enough to consider this a new species, therefore the specimen is determined as Gordius sp. . Heinze's determination as G. setiger might be based on the presence of areoles, however, the elevtions are so slight that it is not sure whether these can really be called areoles.

Material examined. V6826 (2 males and one specimen of unknown sex, posterior end is missing). Fig. 4A, B.

Location. China, province Fokien, Futschou.

Remarks from the catalogue. Collected by "Cons. G. Siemssen" (no date given). Received by the museum on April 4, 1906.

Occurs in publications. unknown

Remarks. The specimen has a smooth cuticle (Fig. 4A). The posterior end has a broad postcloacal crescent directly at the point of bifurcation of the two tail lobes (Fig. 4B). Scattered bristles were observed on the posterior end of one male on the entire tail lobes extending to lateral of the cloacal opening. Due to some covering with dirt, such bristles could not be observed in the other male. Details such as bristles are not very well known from Asian species of Gordius and the specimen is kept here as Gordius sp.

Material examined. V7456 (1 female). Fig. 4C.

Location. China, province Fujian (as "Prov. FoKien").

Remarks from the catalogue. collected by "Consul G. Siemssen" (no date given), received by the museum on September 8, 1911. Determined as "Gordius" by Angener or Augener (as “Ang. det. 1931” or “Aug. det. 1931”).

Occurs in publications. unknown

Remarks. The specimen has a smooth body cuticle (Fig. 4C), therefore no further determination is possible.

Material examined. V7724 (1 male). Fig. 4D, E.

Location. China, province Fujian (as "Prov. Fokien").

Remarks from the catalogue. collected by "Consul G. Siemssen" (no date given), received by the museum on September 4, 1912. Determined as "Gordiide". 
Occurs in publications. unknown

Remarks. The body cuticle is smooth (Fig. 4D). The posterior end has the postcloacal crescent (Fig. 4E), which is characteristic for the genus Gordius. Parts of the posterior end are shrunken or covered with dirt, therefore no further structures could be observed and no further determination could be made.

Material examined. V8077 (1 male). Fig. 4F, G.

Location. Italy, Sorgono, Sardinia.

Remarks from the catalogue. collected by A.H. Krause (no date given), received by the museum on March 14, 1913. Determined as "Gordius".

Occurs in publications. unknown

Remarks. The cuticle is not in good shape, but it appears to be smooth (Fig. 4G), except for the posterior end, where some decent structuring into shallow areoles is present. The posterior end has a semicircular postcloacal crescent extending onto the tail lobes (Fig. 4F), some bristles are present in the posterior part of the inner side of the tail lobes. This description does not really fit present descriptions, but differences are not very large, therefore the specimen is kept here as Gordius sp. .

Material examined. V9075 (2 females). Fig. 4H.

Location. France, surroundings of Montpellier.

Remarks from the catalogue. collected by K. Schmalfuss (no date given). Received by the museum on December 23, 1920. Originally determined as "Gordiide". Although the catalogue indicates only one specimen, two females were found in the vial, named here (I) and (II).

Occurs in publications. unknown

Remarks. Both specimens have a smooth cuticle covered by some dirt (Fig. 4H). Therefore they belong to the genus Gordius, but a further determination is not possible.

Material examined. V9214 (unknown sex, because posterior end is missing). Fig. 4I.

Location. Chile, Victoria in province Malleco (swimming in river).

Remarks from the catalogue. collected by C. Bock in February 1920. Received by the museum on August 12, 1921 .

Occurs in publications. unknown

Remarks. The cuticle is smooth (Fig. 4I), therefore this specimen must belong to the genus Gordius, but a further determination is not possible, because the posterior end is missing.

Material examined. V10154 (1 male). Fig. 4J.

Location. Germany, Hamburg, Süderelbe (river Elbe).

Remarks from the catalogue. Collected by N. Peters (date only given), received by the museum on June 7, 1927. Determined by Heinze in 1935 as Gordius muelleri (as mülleri).

Occurs in publications. unknown.

Remarks. Unfortunately the posterior end of this specimen was lost during preparation for SEM, but it was a male posterior end with a postcloacal crescent. The cuticle is smooth (Fig. 4J).

Material examined. V10529 (1 male). Fig. 4K, L.

Location. Brazil, Itatiaia, state of Rio de Janeiro, $700 \mathrm{~m}$, in a puddle.

Remarks from the catalogue. Collected by F. Ohaus (date unknown), donated to the museum by Titschak, received by the museum on March 15, 1928.

Occurs in publications. unknown

Remarks. This specimen clearly belongs to the genus Gordius due to the presence of a postcloacal crescent (Fig. 4L), but the cuticle is in bad shape (Fig. 4K) and a further determination cannot be given.

Material examined. V10599 (1 male). Fig. 4M-O.

Location. probably Croatia, Rijeka. Writing in catalogue: "Umgeg. v. Fiume", Fiume is the Italian and Hungarian name for Rijeka (source: Wikipedia). This is supported by the added word "Jugoslavien" (Yugoslavia) in different handwriting.

Remarks from the catalogue. no collector indicated, given to the museum by de Gries. Received by the museum on September 24, 1928. Additional remark: from Lacerta muralis (common wall lizard).

Occurs in publications. unknown

Remarks. This is a Gordius specimen with smooth cuticle (Fig. 4M), but with roundish areoles in the posterior end. Some bristles were found on the edge of the tail lobes (Fig. 4O), but a further determination cannot be given. Lizards are not known and extremely unlikely as hosts. As no further specification of where the worm was found in relation to the lizard is given, it cannot be excluded that the worm has been eaten by the lizard and was found in the mouth.

Material examined. V10955 (1 male). Fig. 5A.

Location. Germany, stream Linau in Witzeeze, Schleswig-Holstein.

Remarks from the catalogue. Collected by G. Duncker (date only given on label in vial: August 26, 1929), received by the museum on September 2, 1929. Determined by Heinze in 1935 as Gordius setiger. (label in vial says: "Gordius spec. setiger oder mülleri. Vermutl. doch setiger Schneider”).

Occurs in publications. Heinze (1937, page 316), Heinze (1941, page 58).

Remarks. Unfortunately the posterior end of this specimen was lost during preparation for SEM, but it was a male posterior end with a postcloacal crescent. There are flat areoles (Fig. 5A), which are present in several species, therefore the determination cannot go beyong Gordius sp.

Material examined. V11466 (1 male and fragments of probably 2 further specimens; only male was investigated). Fig. 5B, C.

Location. Brazil, Boiteuxburgo, Santa Catarina.

Remarks from the catalogue. Collected by Paul Missfeldt (no date given). Received by the museum on December 5, 1930. Originally determined as "Gordius". 
Occurs in publications. unknown

Remarks. The body cuticle is smooth (Fig. 5B). The postcloacal crescent is semicircular (Fig. 5C). Few bristles are present along the lateral sides, extending onto the tail lobes. The fine structure of species of Gordius from South America is not well known and therefore this specimen cannot be determined further than to Gordius sp.

\section{Material examined. V11943 (1 male). Fig. 5D, E.}

Location. Hungary. No further specification is given here, but number V11942 is also listed in the catalogue as a gordiid, with the same collector and location "Ungarn, Warmbad Villach, Thermenabfluss". This means the worm was found in the drainage of a spa. Today, Villach is a village in Austria, until 1918 Austria and Hungary were united, which could explain the catalogue entry. It is assumed that the same locality is valid also for V11943. A vial V11942 is present in the collection, but it contains no specimen.

Remarks from the catalogue. Collected by Gebhard (no date given) and received by the museum on September 28, 1933. Original determination as "Gordiiden".

Occurs in publications. unknown

Remarks. The specimen has a postcloacal crescent bordering the point of bifurcation of the tail lobes (Fig. 5E) and the cuticle is smooth (Fig. 5D). Some bristles appear to be present in the posterior end on the sides of the tail lobes.

Material examined. V12712 (1 female). Fig. 5F. Location. Germany, Schiffbeker Moor, Hamburg.

Remarks from the catalogue. Collected by Mrs. Helme (date unknown) and received by the museum on October 12, 1937.

Occurs in publications. unknown

Remarks. The cuticle is smooth (Fig. 5F), a further determination cannot be given.

Material examined. V13285 (1 male)

Location. Japan, Katsura river, Arashiyama, Kyoto prefecture $\left(35^{\circ} 00^{\prime} 48^{\prime \prime} \mathrm{N}, 135^{\circ} 40^{\prime} 40^{\prime \prime} \mathrm{E}\right)$.

Remarks from the catalogue. Collected by Kazuo Isobe on March 13, 2008.

Occurs in publications. Schmidt-Rhaesa and Urabe (2009).

Remarks. This male Gordius specimen could not be determined further, see Schmidt-Rhaesa and Urabe (2009) for further information and discussion.

Material examined. V13305 (1 male)

Location. Japan, Kumano, Misen.

Remarks from the catalogue. Collected by Takuya Sato on September 14, 2009. Received by the museum in 2011.

Occurs in publications. Sato et al. (2012)

Remarks. Specimen is a voucher for a phylogenetic analysis in Sato et al. (2012).

\section{Material examined. V13306 (1 male)}

Location. Japan, Kumano, Nadani.
Remarks from the catalogue. Collected by Takuya Sato on October 14, 2007. Received by the museum in 2011.

Occurs in publications. Sato et al. (2012)

Remarks. Specimen is a voucher for a phylogenetic analysis in Sato et al. (2012).

\section{Material examined. V13307 (1 male)}

Location. Japan, Arida, Ninomata.

Remarks from the catalogue. Collected by Takuya Sato on September 30, 2009. Received by the museum in 2011 .

Occurs in publications. Sato et al. (2012)

Remarks. Specimen is a voucher for a phylogenetic analysis in Sato et al. (2012).

Material examined. V13308 (1 male)

Location. Japan, Arida, Ninomata.

Remarks from the catalogue. Collected by Takuya Sato on September 13, 2009. Received by the museum in 2011.

Occurs in publications. Sato et al. (2012)

Remarks. Specimen is a voucher for a phylogenetic analysis in Sato et al. (2012).

\section{Material examined. V13309 (1 male)}

Location. Japan, Kumano, Nadani.

Remarks from the catalogue. Collected by Takuya Sato on November 10, 2008. Received by the museum in 2011.

Occurs in publications. Sato et al. (2012)

Remarks. Specimen is a voucher for a phylogenetic analysis in Sato et al. (2012).

Material examined. V13310 (1 male)

Location. Japan, Kumano, Nadani.

Remarks from the catalogue. Collected by Takuya Sato on October 15, 2007. Received by the museum in 2011.

Occurs in publications. Sato et al. (2012)

Remarks. Specimen is a voucher for a phylogenetic analysis in Sato et al. (2012).

Material examined. V13311 (1 male)

Location. Japan, Kumano, Nadani.

Remarks from the catalogue. Collected by Takuya Sato on November 15, 2006. Received by the museum in 2011.

Occurs in publications. Sato et al. (2012)

Remarks. Specimen is a voucher for a phylogenetic analysis in Sato et al. (2012).

\section{Gordius aquaticus Linné, 1758}

Material examined. V12685 (1 male). Fig. 5G, H. Location. Germany, Hamburg.

Remarks from the catalogue. Collected by M. Grosse (date not given). Received by the museum on August 5, 1937.

Occurs in publications. unknown. 
Remarks. The cuticle of this specimen is smooth (Fig. $5 \mathrm{G}$ ) and the posterior end (Fig. 5H) does not include any bristles or further structures, therefore this species is determined as G. aquaticus.

\section{Gordius balcanicus Schmidt-Rhaesa, 2010}

Material examined. V13270 (1 male)

Location. Serbia, Kučaj Mountains, Dubašnica, Mikuljska River.

Remarks from the catalogue. Collected by Ajtić on October 3, 2006.

Occurs in publications. Schmidt-Rhaesa (2010).

Remarks. Holotype of this species. See Schmidt-Rhaesa (2010) for all information about this specimen.

\section{Gordius balticus Schmidt-Rhaesa, 2010}

Material examined. V13268 (1 male)

Location. Estonia, South Estonia (exact location unknown), in rainwater barrel.

Remarks from the catalogue. The collector according to the label is "Elli" in 2008.

Occurs in publications. Schmidt-Rhaesa and Prous (2010).

Remarks. Holotype of this species. See Schmidt-Rhaesa and Prous (2010) for all information about this specimen.

Material examined. V13288 (1 female)

Location. Estonia, rainwater container in Suurküla, Häädemeeste.

Remarks from the catalogue. Collected by M. Looring on August 23, 2006.

Occurs in publications. Schmidt-Rhaesa and Prous (2010).

Remarks. Paratype of this species. See Schmidt-Rhaesa and Prous (2010) for all information about this specimen.

\section{Gordius digitatus Schmidt-Rhaesa, 2010}

\section{Material examined. V13271 (1 male)}

Location. Croatia, Plitvice Lakes (Plitvička Jezera).

Remarks from the catalogue. Collected by M. Teiwes on August 8, 2000.

Occurs in publications. Schmidt-Rhaesa (2010).

Remarks. Holotype of this species. See Schmidt-Rhaesa (2010) for all information about this specimen.

\section{Gordius helveticus Schmidt-Rhaesa, 2010}

Material examined. V13272 (1 male)

Location. Swizerland, Meiringen (Berner Oberland), altitude $793 \mathrm{~m}$.

Remarks from the catalogue. Collected by Axel Groenveld on July 18, 2008.
Occurs in publications. Schmidt-Rhaesa (2010).

Remarks. Holotype of this species. See Schmidt-Rhaesa (2010) for all information about this specimen.

Material examined. V13277 (1 male)

Same data as for V13272, paratype of this species. See Schmidt-Rhaesa (2010) for all information about this specimen.

\section{Gordius karwendeli Schmidt-Rhaesa, 2010}

\section{Material examined. V13273 (1 male)}

Location. Germany, Karwendel Mountains, 4-4.5 km NE of Mittenwald. Found in a (not water covered) gravel-bed along stream Seinsbach at roadside during heavy rains.

Remarks from the catalogue. Collected by Maaike van Rijn and Axel Groenveld on June 25, 2002.

Occurs in publications. Schmidt-Rhaesa (2010).

Remarks. Holotype of this species. See Schmidt-Rhaesa (2010) for all information about this specimen.

\section{Gordius longissimus Römer, 1895}

Material examined. V2229 (1 female). Fig. 5I.

Location. "Südsee" (= South Sea), no further specification.

Remarks from the catalogue. Collected by "M.G." (writing not explicit). No collection date given and no date when received by the museum. From Saturnia (Lepidoptera). Determined by Römer in 1893 as G. longissimus, confirmed by Heinze in 1935.

Occurs in publications. Römer (1895, page 796), Römer (1896, page 273), Heinze (1933, page 109), Heinze (1934, page 189).

Remarks. Holotype of this species. Römer (1895) regards this specimen as a new species due to its extreme length and, in comparison to G. fulgur, another species of extreme length, by differences in diameter and colour. Nowadays it is generally assumed that size (length and width) as well as colouration patterns are quite variable, therefore these are no good characters to justify a new species description. One further difference is that $G$. longissimus is lacking an iridescence of the cuticle that G. fulgur has. The morphological reason for such iridescence is unknown. The cuticular surface is smooth (Fig. 5I). This is regarded to be a quite weak description for a species, but no changes of the systematical status are proposed here. The length was measured here as $126 \mathrm{~cm}$, which is close to the $132 \mathrm{~cm}$ given by Römer. Gordiids are somewhat flexible when preserved and a correct length measurement is almost impossible. The host, a butterfly, is unusual for gordiids (see Schmidt-Rhaesa 2013).

\section{Gordius paranensis Camerano, 1892}

Material examined. V5035 (1 male, 2 females). Fig. 5J, K. Location. Paraguay, San Bernardino. 
Remarks from the catalogue. Collected by "Cons. Wiengreen" (no date given). Received by the museum on April 30, 1898. Determined as "Gordius".

Occurs in publications. unknown

Remarks. The male contains in the posterior end a semicircular row of bristles anterior of the cloacal opening (Fig. 5K), this is characteristic for the species $G$. paranensis from South American and New Zealand (see Schmidt-Rhaesa et al. 2000). The two females have a smooth cuticle (Fig. 5J), although they cannot be assigned to a particular species of Gordius they are assumed to be conspecific with the male specimen.

Material examined. V11709 (8 males; 1 male investigated by SEM). Fig. 5L.

Location. Brazil, Boiteuxburgo, Santa Catarina.

Remarks from the catalogue. Collected by Paul Missfeldt (date unknown). Received by the museum on September 8, 1932. Originally determined as "Gordiide".

Occurs in publications. unknown

Remarks. The male contains in the posterior end the semicircular row of bristles characteristic for this species (Fig. 5L).

\section{Gordius pesici Schmidt-Rhaesa, 2010}

Material examined. V13274 (1 male)

Location. Montenegro, Budva.

Remarks from the catalogue. Collected by Vladimir Pešić on September 2, 2006.

Occurs in publications. Schmidt-Rhaesa (2010).

Remarks. Holotype of this species. See Schmidt-Rhaesa (2010) for all information about this specimen.

\section{Gordius plicatissimus Heinze, 1952}

Material examined. V5524 (1 male). Fig. 5M-O.

Location. Swizerland, Grindelwald.

Remarks from the catalogue. Collected by $\mathrm{Mi}$ chaelsen (no date given). Received by the museum on September 15, 1900. Determined as "Gordius". Host: Decticus verrucivorum.

Occurs in publications. unknown

Remarks. Areoles are large, prominent and slightly oval (Fig. $5 \mathrm{~N}$ ), the arrangement is mostly perpendicular to the longitudinal body axis (Fig. 5M). This arrangement mostly corresponds to the description for G. plicatissimus Heinze, 1952, a species reported from Austria (Rosenau am Hengstpaß) (Heinze 1952, see also Schmidt-Rhaesa 2010). The posterior end is strongly shrunken and few details can be observed (Fig. 5O). The postcloacal crescent extends onto the tail lobes, it is broad and parabolic. There are few bristles along the edge of the tail lobes. With exception of the bristles, which were not described by Heinze (1952), the characteristics of the posterior end correspond to G. plicatissimus.

Material examined. V13332 (1 male). Fig. 6A, B.
Location. Austria, Salzburg, St. Gilgen, Falkenstein, $717 \mathrm{~m}$. The specimen was found alive during excavations of a historical source in about $2 \mathrm{~m}$ depth.

Remarks from the catalogue. Collected by an unknown person on August 30, 2011. Donated to the museum by Robert Lindner, Haus der Natur in Salzburg, Austria in July 2012.

Occurs in publications. no

Remarks. Areoles are prominent and slightly oval, the arrangement is perpendicular to the longitudinal body axis (Fig. 6A). The broad postcloacal crescent is angled and extends well onto the tail lobes (Fig. 6B). Tiny bristles are present lateral of the postcloacal crescent and on the tail lobes. These characters correspond well to the description for G. plicatissimus (Heinze 1952, see also Schmidt-Rhaesa 2010).

\section{Gordius cf. polychaetus Tang, 1934}

Material examined. V13283 and V13284 (1 male each)

Location. Japan, Sobu Valley, Kaminyu, Yogo Town, Shiga Prefecture $\left(35^{\circ} 34^{\prime} 14^{\prime \prime} \mathrm{N}, 136^{\circ} 12^{\prime} 41^{\prime \prime} \mathrm{E}\right)$, on the surface of snow.

Remarks from the catalogue. Collected by Daiki Kado on November 22, 2008.

Occurs in publications. Schmidt-Rhaesa and Urabe (2009).

Remarks. Both specimens have numerous fine bristles on their cuticle, which corresponds to the description of G. polychaetus Tang, 1934. See Schmidt-Rhaesa and Urabe (2009) for documentation and discussion.

\section{Gordius serratus Schmidt-Rhaesa, 2010}

Material examined. V13280 (1 male)

Location. Papua New Guinea, Lahamenegu piggery, Goroka, Eastern Highlands Province, from river water.

Remarks from the catalogue. Collected by Ifor Owen, presumably in 1975.

Occurs in publications. Schmidt-Rhaesa (2010).

Remarks. Holotype of this species. See Schmidt-Rhaesa (2010) for all information about this specimen.

\section{Material examined. V13281 (1 male)}

Same data as for V13280, paratype of this species. See Schmidt-Rhaesa (2010) for all information about this specimen.

\section{Gordius setiger Schneider, 1866}

Material examined. V2224 (1 male). Fig. 6C, D.

Location. Germany, Hamburg, Alster.

Remarks from the catalogue. Collected by Graeser (no collection date or date when received by the museum given). Determined by Römer in 1893 as Gordius violaceus and by Heinze in 1935 as Gordius setiger. 
Occurs in publications. Römer (1895, page 794), briefly in Heinze (1937, page 316), Heinze (1941, page 58).

Remarks. The SEM reinvestigation shows inconspicuous areoles (Fig. 6C) and a short, semicircular postcloacal crescent (Fig. 6D). The characters are not very well visible, but correspond to the description for $G$. setiger (see, e.g., Heinze 1941).

Material examined. V5940 (1 male). Fig. 6E-G.

Location. Germany, river Elbe close to Lauenburg.

Remarks from the catalogue. Collected by "Wilh. Meyer" on June 1, 1902. Received by the museum on July 1, 1902. Determined by Heinze in 1935 as Gordius mülleri.

Occurs in publications. Heinze (1937, page 320), Heinze (1941, page 59)

Remarks. Areoles on the cuticle are roughly polygonal in shape and attach closely to each other (Fig. 6E). Few areoles appear a bit stretched, i.e. are broader than long. The narrow, semicircular postcloacal crescent is directly at the point of bifurcation of the tail lobes (Fig. 6F, $\mathrm{G})$. The cloacal opening is covered by dirt, but appears to be slightly oval (Fig. 6G). Heinze's determination as G. muelleri cannot be supported here. Gordius muelleri has areoles with broad interareolar spaces, a broad postcloacal crescent in distinct distance from the point of bifurcation of the tail lobes and an oval cloacal opening (e.g. Heinze 1941). Shape and position of the postcloacal crescent, in addition to the mostly polygonal areoles correspond with $G$. setiger, although the slightly oval cloacal opening and some "stretched" areoles are not completely corresponding characters.

\section{Gordius cf. setiger Schneider, 1866}

Material examined. V9000 (1 male). Fig. 6H-J.

Location. Germany, lake "Behler See" near Timmendorf, Holstein.

Remarks from the catalogue. collected by "Gast" with unknown date. Received by the museum on June 15, 1920. Determined by Heinze in 1935 as Gordius setiger.

Occurs in publications. Heinze (1937, page 316), Heinze (1941, page 58)

Remarks. The two species $G$. setiger and $G$. albopunctatus are very similar and differ only in few details. According to Heinze (1941), G. albopunctatus has polygonal areoles that are slightly stretched and their longer axis is perpendicular to the longitudinal body axis. Gordius setiger also has polygonal areoles, but they are irregularly polygonal without being stretched. Gordius albopunctatus has a parabolic postcloacal crescent, while this is semicircular in G. setiger. The specimen V9000 has clearly visible areoles that are slightly stretched as in G. albopunctatus (Fig. 6H). The postcloacal crescent, however, is semicircular as in G. setiger (Fig. 6I, J). The position of the cloacal opening in V9000 is directly anterior of the postcloacal crescent (Fig. 6I, J), while in both species, G. albopunctatus and G. setiger, there is some distance between these two structures. In summary, V9000 is intermediate between G. setiger and $G$. albopunctatus, which could hint to some yet unknown intraspecific variation.

Material examined. V9900 (2 males). Fig. 6K-P.

Location. Germany, Hamburg, river Elbe, Parkhafen (writing is not explicit).

Remarks from the catalogue. collected by $\mathrm{H}$. Meves (date not given). Received by the museum on May 29, 1925. Originally determined as "Gordiiden". On the vial label, but not in the catalogue is written: determined as Gordius setiger by R. Arndt in 1968.

Occurs in publications. unknown

Remarks. The two males of this lot show characters as described above for $G$. setiger and G. albopunctatus (see above under V9000). Male I has polygonal areoles (Fig. 6K), part of which appears to be stretched as in G. albopunctatus. The postcloacal crescent is semicircular as in G. setiger (Fig. 6L, M). Male II has polygonal, unstretched areoles as in G. setiger (Fig. 6N) and a narrow, but parabolic postcloacal crescent as in $G$. albopunctatus (Fig. 6O, P). Therefore, these two males support the discussion under V9000 that there are intermediate stages between the two species $G$. setiger and G. albopunctatus.

\section{Gordius spiridonovi Schmidt-Rhaesa, 2010}

Material examined. V13286 (1 male)

Location. Estonia, Lake Peipsi (about $58^{\circ} 40^{\prime} \mathrm{N}$, $\left.27^{\circ} 30^{\prime} \mathrm{E}\right)$.

Remarks from the catalogue. Collected by an unknown person on June 9, 1980.

Occurs in publications. Schmidt-Rhaesa and Prous (2010).

Remarks. Holotype of this species. See Schmidt-Rhaesa and Prous (2010) for all information about this specimen.

Material examined. V13287 (1 male)

Location. Russia, Udoha River (tributary of the Shelon River), near Borovit, Pskov Region.

Remarks from the catalogue. Collected by T. Timm on July 7, 1971.

Occurs in publications. Schmidt-Rhaesa and Prous (2010).

Remarks. Paratype of this species. See Schmidt-Rhaesa and Prous (2010) for all information about this specimen.

\section{Gordius terminosetosus Schmidt-Rhaesa, 2010}

Material examined. V13279 (1 male)

Location. Estonia, Sauga Stream, western Estonia $\left(58^{\circ} 31.54^{\prime} \mathrm{N}, 24^{\circ} 42.16^{\prime} \mathrm{E}\right)$.

Remarks from the catalogue. Collected by H. Timm on August 16, 1993. 
Occurs in publications. Schmidt-Rhaesa and Prous (2010).

Remarks. Holotype of this species. See SchmidtRhaesa and Prous (2010) for all information about this specimen.

\section{Gordius undulatus Heinze, 1937}

Material examined. V5521 (1 male). Fig. 7A, B.

Location. Germany, Hamburg, Winterhude.

Remarks from the catalogue. Collected by Braun (writing not explicit, but this name is given by Heinze 1941) on August 10, 1900. Received by the museum on September 1, 1900, determined by "Heinze 1935/6" as Gordius undulatus.

Occurs in publications. Heinze (1937, page 320), Heinze (1941, page 60).

Remarks. This is the holotype for this species. (Heinze 1937, see also 1941) describes characteristic features as follows: the posterior end has a small crescent-shaped postcloacal crescent, which is at some distance from the point of bifurcation of the tail lobes. The cloacal opening is round. The cuticle has clearly visible areoles which are irregularly shaped and partly form indentations. These characteristics could be confirmed by the SEM reinvestigation only in part. The shape of the postcloacal crescent is as given by Heinze (1937), but its distance from the point of bifurcation of the tail lobes is difficult to determine (Fig. 7B). The posterior end is slightly curled along the ventral side and the anterior region between the tail lobes is filled with dirt. I have the impression that there is no distance between the postcloacal crescent and the point of bifurcation, but this is not certain. The cuticle was investigated adjacent to the region, where Heinze had removed a piece for his investigation. The cuticle is partly covered by contamination and areoles appear not as clear as stated by Heinze (1937). They are mostly polygonal in shape (Fig. 7A), but some indentations occur.

\section{Gordius zwicki Schmidt-Rhaesa, 2010}

\section{Material examined. V13275 (1 male)}

Location. Russia, Russian Far East, small forest tributary in the upper course of Milogradovka River, $25 \mathrm{~km}$ NW of Milogradovo.

Remarks from the catalogue. Collected by Peter Zwick on June 13, 1998.

Occurs in publications. Schmidt-Rhaesa (2010).

Remarks. Holotype of this species. See Schmidt-Rhaesa (2010) for all information about this specimen.

\section{Material examined. V13276 (1 male)}

Same data as for V 13275, paratype of this species. See Schmidt-Rhaesa (2010) for all information about this specimen.

\section{Genus Nectonema Verrill, 1897}

Nectonema is the only marine genus of horsehair worms (Nematomorpha) and includes 5 species. Two of them $(N$. agile, N. munidae) were repeatedly found, all other species were only caught on single occasions.

\section{Nectonema munidae Brinkmann, 1930}

Material examined. V13289 (2 females)

Location. Norway, Korsfjorden near Bergen, 550$700 \mathrm{~m}$.

Remarks from the catalogue. Collected by A. Schmidt-Rhaesa, Martin V. Sørensen, Reinhardt Møbjerg Kristensen and Henrik Glenner in August 2009. From host Munida tenuimana.

Occurs in publications. none.

Remarks. none.

\author{
Material examined. V13290 (2 males) \\ Location. Norway, Korsfjorden near Bergen, 550- \\ $700 \mathrm{~m}$.
}

Remarks from the catalogue. Collected by A. Schmidt-Rhaesa, Martin V. Sørensen, Reinhardt Møbjerg Kristensen and Henrik Glenner in August 2009. From host Munida tenuimana.

Occurs in publications. none.

Remarks. none.

\section{Genus Parachordodes Camerano, 1897}

Species in this genus have two types of areoles, the second, larger type are large areoles that seem to be fusion products of several smaller areoles (Schmidt-Rhaesa 2002a, 2013). They are called superareoles. In total 15 species are known. Several additional specimens without superareoles have been described as Parachordodes and not formally removed from this genus, yet (Schmidt-Rhaesa 2013).

\section{Parachordodes tolosanus (Dujardin, 1842)}

Material examined. V2220 (3 males and 2 females are indicated in the catalog, but actually only 2 males and 1 female are present; female transferred to new catalogue number, see below). Fig. $11 \mathrm{~K}-\mathrm{M}$.

Location. Göttingen, Hainholz, in source (Germany).

Remarks from the catalogue. Collected by Schlotthauber (no collection date or date when received by the museum given). Determined by Römer in 1893 as Gordius violaceus, corrected by Heinze in 1935 to Parachordodes tolosanus.

Occurs in publications. Römer (1895, page 794), probably Heinze (1937, page 283) and Heinze (1941, page 26).

Remarks. Collector and collection dates are similar to V2218 determined as Gordionus wolterstorffii. The fate of two missing specimens is unknown. Two specimens 
( 1 male and 1 female) were reinvestigated by SEM. The cuticle of the male contains superareoles (Fig. 11K) and corresponds to the description of $P$. tolosanus (see, e.g., Heinze 1941). The female does not have superareoles, but only one type of areoles, it is therefore designed as Gordionus sp. under the new catalogue number V13361.

Material examined. V2236 (I) (1 male) One specimen is indicated in the catalogue, but 2 specimens are present. The second specimen is determined as Gordionus sp.; Fig. 11N, O.

Location. Göttingen, Germany

Remarks from the catalogue. Collected by Schlotthauber (no collection date or date when received by the museum given). Determined by Schlotthauber in 1854 as Gordius aquaticus, corrected by Heinze in 1935 to Parachordodes tolosanus. Host: Harpalus ruficornis crossed out and replaced by Ophonus cephalotes.

Occurs in publications. Heinze (1937, page 285), Heinze (1941, page 24).

Remarks. Superareoles are present (Fig. 11N, O), therefore the determination as $P$. tolosanus is confirmed. A second specimen was found in the vial, which shows a different cuticular pattern and which is here determined as Gordionus sp. (V2236 II). As the catalogue indicates only one specimen, it is unknown whether this second specimen does belong to the vial originally. If it does, it is unknown whether both specimens emerged from the beetle.

Material examined. V2237 (1 male). Fig. 11P, Q.

Location. Göttingen, Germany

Remarks from the catalogue. Collected by Schlotthauber (no collection date or date when received by the museum given). Determined by Schlotthauber in 1854 as Gordius aquaticus, corrected by Heinze in 1935 to Parachordodes speciosus. Host: Harpalus distinguendus.

Occurs in publications. Heinze (1937, page 285), Heinze (1941, page 24).

Remarks. SEM reinvestigation shows superareoles on the cuticle (Fig. 11P) that correspond to those described from $P$. tolosanus rather than those for P. speciosus (see Heinze 1941).

\section{Genus Paragordionus Heinze, 1935}

The genus Paragordionus resembles Gordionus in many respects, but the cuticle contains two types of areoles. The larger areoles are clustered together, such clusters can be composed of two or of several areoles. The large areoles are called megareoles (see Schmidt-Rhaesa 2002a, 2013, Schmidt-Rhaesa and Wagner 2013). Only five species have been described, and species limits require further investigations (Schmidt-Rhaesa and Wagner 2013).

\section{Paragordionus dispar (Müller, 1926)}

Material examined. V7449 (II) (1 male). Fig. 11I, J.

Location. Germany, Berchtesgaden.

Remarks from the catalogue. Collected by "Heinr. Baur" (not well readable) (no date given). Received by the museum on August 1, 1911. Determined by Heinze in 1935 as Paragordionus dispar. Although the catalogue says that only one specimen belongs to this lot, two specimens are present. These are marked with (I) and (II).

Occurs in publications. Heinze (1935b, page 677), Heinze (1937, page 276), Heinze (1941, page 18).

Remarks. The two specimens (I) and (II) both belong to the genus Paragordionus, because they possess clusters of megareoles (see Schmidt-Rhaesa 2002a). In specimen (II) the clusters of megareoles are smaller and include maximally three megareoles (Fig. 11I, J), while in specimen (I) clusters are larger and include clusters of up to seven megareoles (Fig. 11F, H). These differences correspond to the published descriptions of two different species, $P$. dispar and $P$. vejdovskyi (see, e.g., Heinze 1941). However, according to results of Schmidt-Rhaesa and Wagner (2013) the size and composition of the clusters are quite variable and species limits in this genus should be reinvestigated. As specimen (II) corresponds to the determination given by Heinze, it is assumed that this is the specimen he investigated and reported in the literature. Where the second specimen (I) comes from, whether it was originally present, but overlooked or whether it was added later is unknown and cannot be reconstructed.

\section{Paragordionus ibericus Schmidt-Rhaesa \& Cieslak, 2008}

\section{Material examined. V13260 (1 male)}

Location. Spain, Puerto de los Cotos, Arroyo de la Laguna Grande de Penalara (4049'59"N, 356'09"W), 1600 m.

Remarks from the catalogue. Collected by I. Ribera and A. Cieslak on July 1, 2006. Received by the museum on July 3, 2008.

Occurs in publications. Schmidt-Rhaesa and Cieslak (2008).

Remarks. Holotype of this species. See Schmidt-Rhaesa and Cieslak (2008) for all information about this specimen.

Material examined. V13261 (1 male)

Same data as V13260 (but no type material), see there.

\section{Paragordionus vejdovskyi (Janda, 1894)}

Material examined. V7449 (I) (1 male). Fig. 11F-H.

Location. Germany, Berchtesgaden.

Remarks. See V7449 (II) under Paragordionus dispar for all remarks and explanations. 


\section{Genus Paragordius Camerano, 1897}

Specimens belonging to this genus are easy to recognize, because females have three lobes around the central and terminal cloacal opening and males have very long paired tail lobes (length: width 2:1 or longer). This genus includes the only species among Nematomorpha, where parthenogenetic reproduction was shown ( $P$. obamai; Hanelt et al. 2012), the type material is in the collection (see below).

\section{Paragordius sp.}

Material examined. V3039 (2 males). Fig. 8A-D.

Location. Mexico, Hacienda de Ixtapa Tepic.

Remarks from the catalogue. Collected by Dr. P. (?) Hacker (no date given). Received by the museum on October 2, 1908. Determined as "Gordiide". Only 1 male is registered in the catalogue, while 2 males were found in the vial.

Occurs in publications. unknown

Remarks. The long tail lobes of the male posterior end are characteristic for the genus Paragordius (Fig. 8C, D), but no further characters could be identified to determine the exact species.

Material examined. V8948 (1 female). Fig. 8E, F.

Location. Chile, river Estero Manco (as "Fluss Manco") near Coronel.

Remarks from the catalogue. Collected by R. Paessler on December 16, 1915, received by the museum on January 15,1920 . Originally determined as "Gordiide".

Occurs in publications. unknown

Remarks. The posterior end has three lobes, two broader and a slender one, which is typical for females of the genus Paragordius (Fig. 8F). The cuticle contains regular depressions and also longitudinal fissures (Fig. 8E). This character does not correspond to previous descriptions of species of Paragordius, but because part of the characters might be artificial, more specimens should be investigated before calling this a new species.

Material examined. V8962 (1 female). Fig. 8G, H.

Location. Chile, river Estero Manco (as "Fluss Manco") near Coronel.

Remarks from the catalogue. Collected by R. Paessler in January 1917, received by the museum on January 15, 1920. Originally determined as "Gordiide".

Occurs in publications. unknown

Remarks. The posterior end has three lobes, two broader and a slender one, which is typical for females of the genus Paragordius (Fig. 8H). The cuticle appears to be smooth, but has many small cracks (Fig. 8G), which is probably artificial.
Paragordius obamai Hanelt, Bolek \& Schmidt-Rhaesa, 2012

Material examined. V13265-13267 (1 female each number)

Location. Reared from a cyst from a Biomphalaria pfeifferi snail collected at Kasabong stream, a small stream in Nyanza province, Kenya (approx. $1170 \mathrm{~m}$ altitude), which flows into Winam Bay of Lake Victoria, $2 \mathrm{~km}$ to the south.

Remarks from the catalogue. Received from Ben Hanelt.

Occurs in publications. Hanelt et al. (2012).

Remarks. V13265 is the holotype for this species, V13266 and V13267 are paratypes. See Hanelt et al. (2012) for all information about this specimen. Paragordius obamai is the only known nematomorph reproducing by parthenogenesis.

\section{Genus Pseudochordodes Carvalho, 1942}

Pseudochordodes is a genus with distribution from the southwestern Nearctic to the Neotropis. Eight species have been described. The males have an unbranched posterior end (= without tail lobes) and the cuticle of both sexes has two types of areoles (see Schmidt-Rhaesa 2013 for summary).

\section{Pseudochordodes meridionalis Carvalho \& Feio, 1950}

Material examined. V2930 (1 female). Fig. 12A, B.

Location. Guatemala

Remarks from the catalogue. From bequest of " $O$. Hoffmann der Jul. Groth". Received by the museum on February 14, 1908. Originally determined as "Chordodes".

Occurs in publications. unknown

Remarks. SEM reinvestigation reveals larger and smaller areoles (Fig. 12A, B) in an arrangement that corresponds to the description of Pseudochordodes meridionalis (see, e.g., Carvalho and Feio 1950, De Miralles and De Villalobos 1996, De Villalobos et al. 2005, 2008 [in part as Neochordodes meridionalis]). The cuticle contains areoles with an apical tubercle (Fig. 12B), such areoles appear also to be present in the specimen figured by De Villalobos et al. (2005, her Fig. 6B) and have not been described for this genus before.

\section{Undetermined}

Material examined. V2226 (1 female). Fig. 16A.

Location. USA, Arizona, Prescott.

Remarks from the catalogue. Collected by Rodenburg (written in Römer 1895 as Bodenburg) (no collection date or date when received by the museum given). Determined by Römer in 1893 as Gordius violaceus, determination confirmed by Heinze in 1935. 
Occurs in publications. Römer (1895, page 794), briefly in Römer (1896, page 267).

Remarks. The cuticle of this specimen shows areoles with no clear border and no interareolar structures (Fig. 16A). The surface of the areoles contains grooves, which are oriented parallel to the longitudinal body axis (Fig. 16A). There are regions between the areoles, where grooves are more numerous and create somewhat like a dense cluster of cuticular cords. There is some resemblance to Pseudochordodes gordioides, which is present in the Southwestern USA, but here a second type of areoles is more pronounced and has a different surface structure (see, e.g. Schmidt-Rhaesa et al. 2003). Therefore it is not clear to which genus or species this specimen belongs.

Material examined. V2233 (1 male). Fig. 16B, C. Location. "Bahia"

Remarks from the catalogue. Collected by Bolau (no date given). Received by the museum on September 23, 1893. Determined by Römer in 1893 as C. variopapillatus, holotype of this species. Heinze in 1935 writes "specimen in bad condition, not to determine [sehr schlecht erhalten, indeterminable]" and replaces "C. variopapillatus" by "Gordius spec.?".

Occurs in publications. Römer (1895, page 800), briefly in Römer (1896, page 287), Heinze (1935a, page 23 ).

Remarks. The specimen is indeed in bad condition. No areoles were observed on the cuticle (Fig. 16B), therefore, the assignment to Chordodes is certainly wrong. As Römer (1895) described different kinds of "papillae" (= areoles) it appears likely that the current specimen is not the specimen investigated by Römer. SEM investigation reveals numerous tube-like structures (Fig. 16B, C), similar structures have been described by Schmidt-Rhaesa et al. (2001) and were assumed not to be cuticular structures. Heinze (1935a) has interpreted these structures as fungal hyphae that break through the cuticle.
Material examined. V5522 (1 specimen, sex unknown). Fig. 16D, E.

Location. Germany, Ahrensburg.

Remarks from the catalogue. Collected by Post (no date given). Received by the museum on September 8, 1900. Determined by Heinze in 1935 as "Gordius? undulatus".

Occurs in publications. unknown (not in Heinze 1937 and 1941).

Remarks. The posterior end is damaged, the sex cannot be determined. The cuticle is heavily covered with some covering, probably fungus (Fig. 16D, E). In some parts areoles are visible, these are irregularly shaped. The presence of areoles is in agreement with an assignment to the genera Gordius or Gordionus, but a further determination cannot be given.

Material examined. V6622 (sex not determined). Fig. $16 \mathrm{~F}, \mathrm{G}$.

Location. Germany, Hamburg.

Remarks from the catalogue. Collected by Rump (no date given). Received by the museum on November 10, 1904. Host: Vanessa io (European peacock, currently Aglais io or Inarchis io, Lepidoptera).

Occurs in publications. unknown

Remarks. The cuticle is smooth and has some folds (Fig. 16F, G), but no proper determination is possible. Lepidoptera are not or only exceptionally host to nematomorphs (see Schmidt-Rhaesa 2013), therefore this specimen might not be a horsehair worm.

Material examined. V7028 (1 specimen). Fig. 16H.

Location. Portugal, Leixões

Remarks from the catalogue. Collected by F. Ohaus on August 25, 1904. Received by the museum on January 1, 1907. Determined as "Gordiide".

Occurs in publications. unknown

Remarks. Cuticle smooth, covered with dirt or fungi (Fig. 16H), no proper determination possible. 

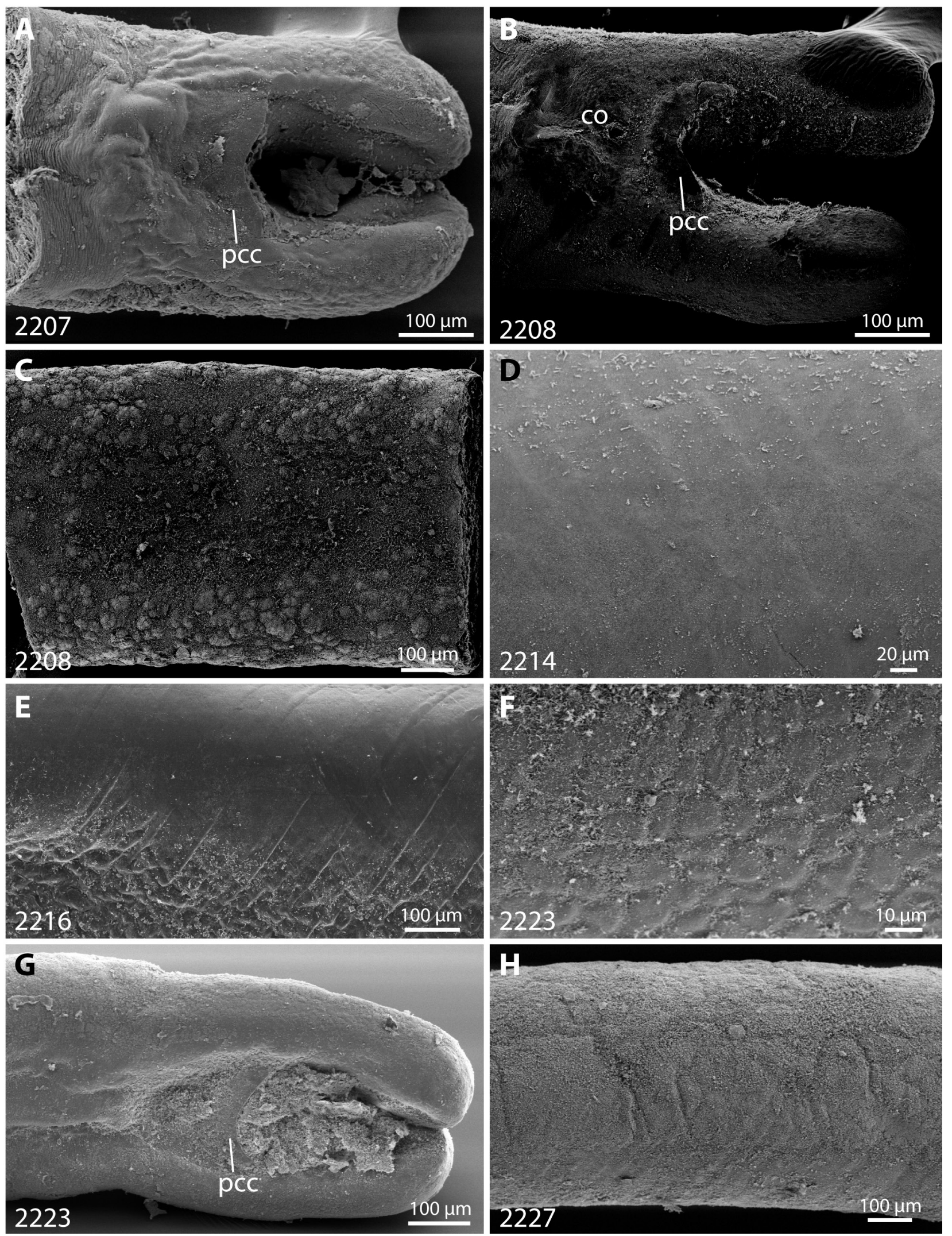

Figure 1. Specimens of Gordius sp., ventral view of posterior ends and cuticle in midbody sections. The specimen number is indicated in the lower left of each image. A, B, G. Posterior ends with postcloacal crescent (pcc) and cloacal opening (co). The cuticular surface $(\mathbf{C}-\mathbf{F}, \mathbf{H})$ is in some cases covered with encrusting material $(\mathbf{C})$ or dirt $(\mathbf{F}, \mathbf{H})$. Diagonal lines are created by muscular fibers underlying the cuticle. 


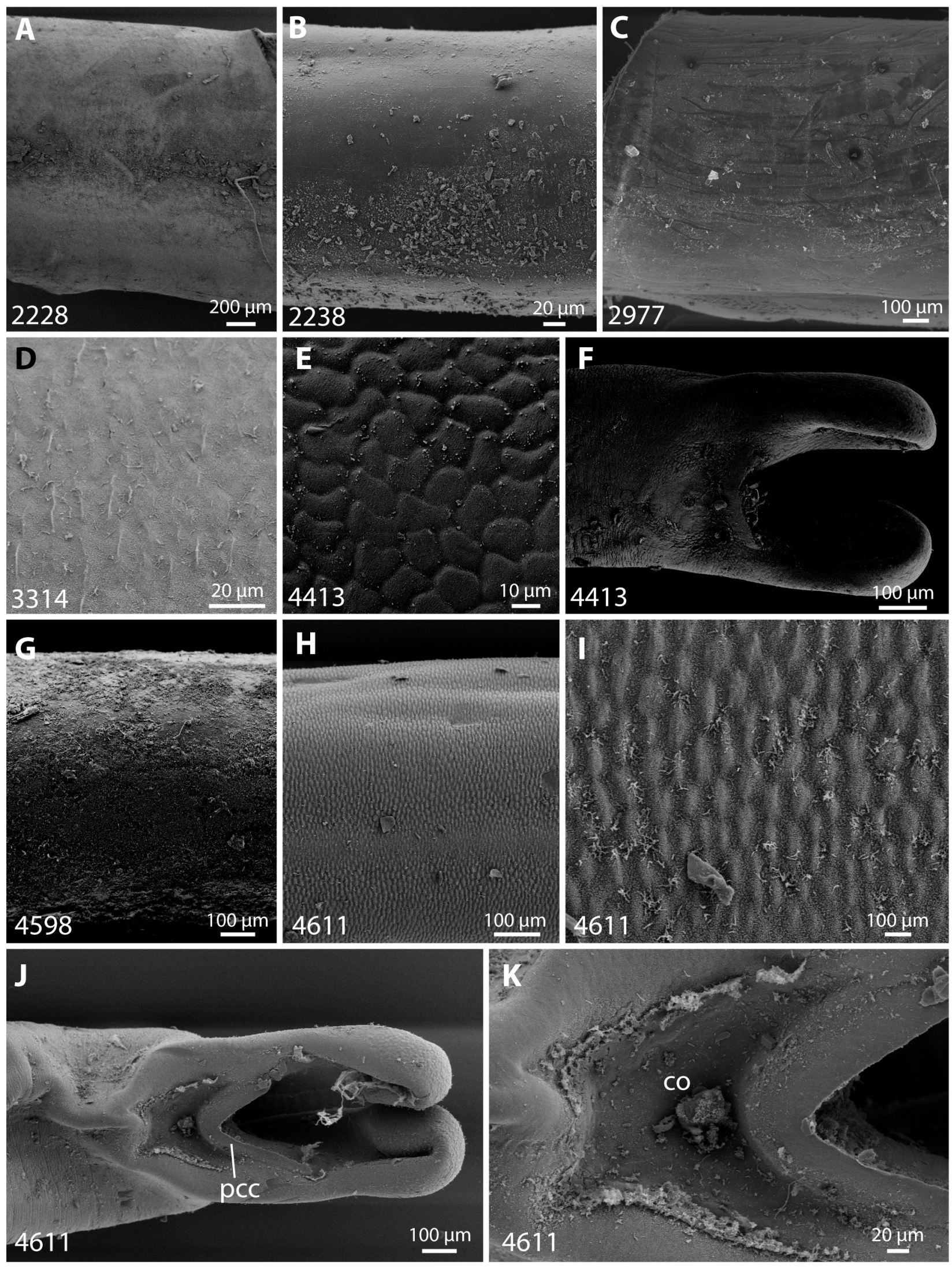

Figure 2. Specimens of Gordius sp., ventral view of posterior ends and cuticle in midbody sections. The specimen number is indicated in the lower left of each image. A-E, G-I. Cuticular surface. This is either smooth (A-C, G), has keel-like structures (D) or areoles (E, H, I). F, J, K. Posterior ends with postcloacal crescent (pcc) and cloacal opening (co). The posterior end of specimen V4611 has a fringed rim around the cloacal opening $(\mathbf{J}, \mathbf{K})$. 


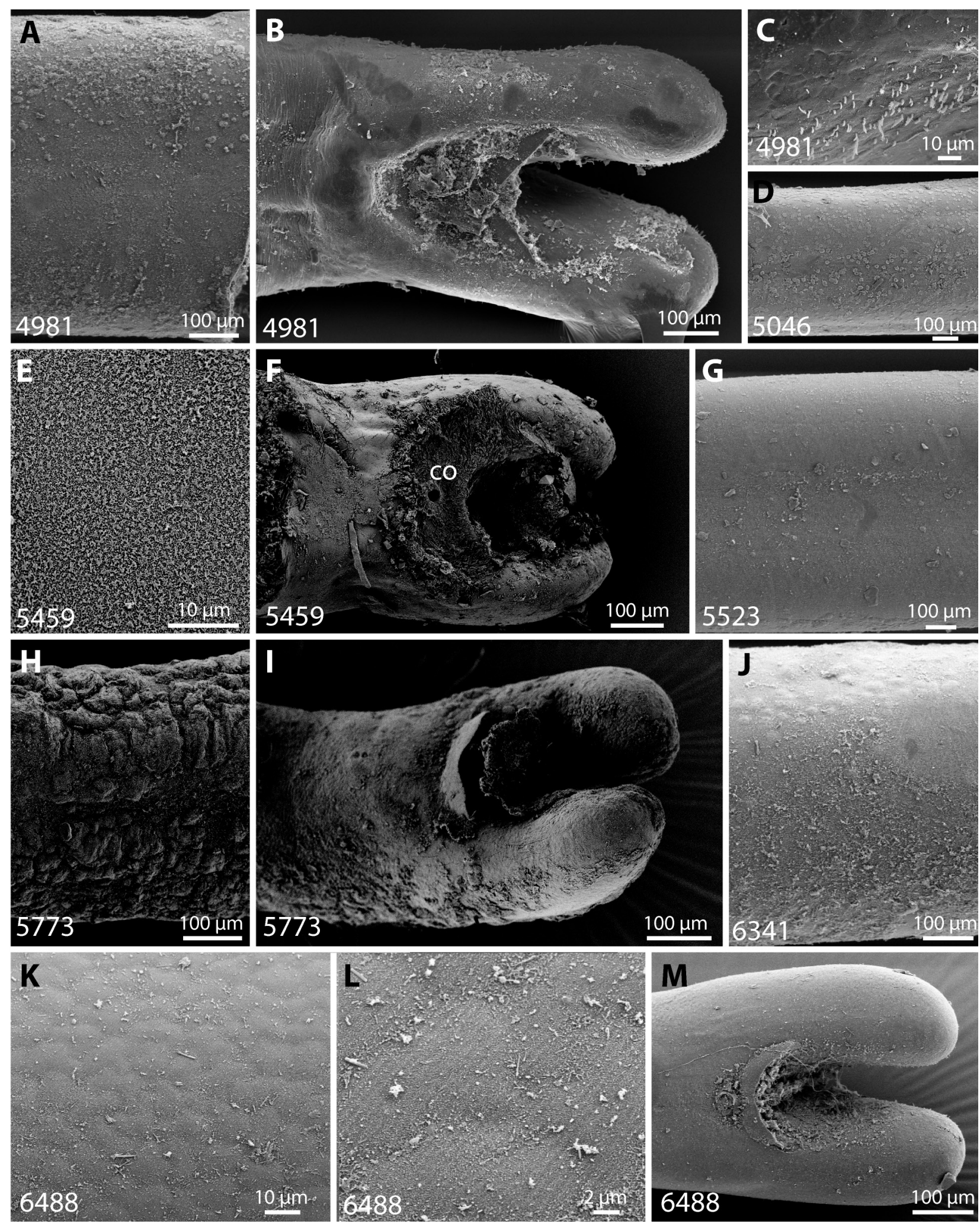

Figure 3. Specimens of Gordius sp., ventral view of posterior ends and cuticle in midbody sections. The specimen number is indicated in the lower left of each image. A, D, E, G, H, J-L. Cuticular surface, see text for explanation. B, F, I, M. Posterior ends with postcloacal crescent and cloacal opening (co). C. Magnification of short bristles on the tail lobes of V4981. 

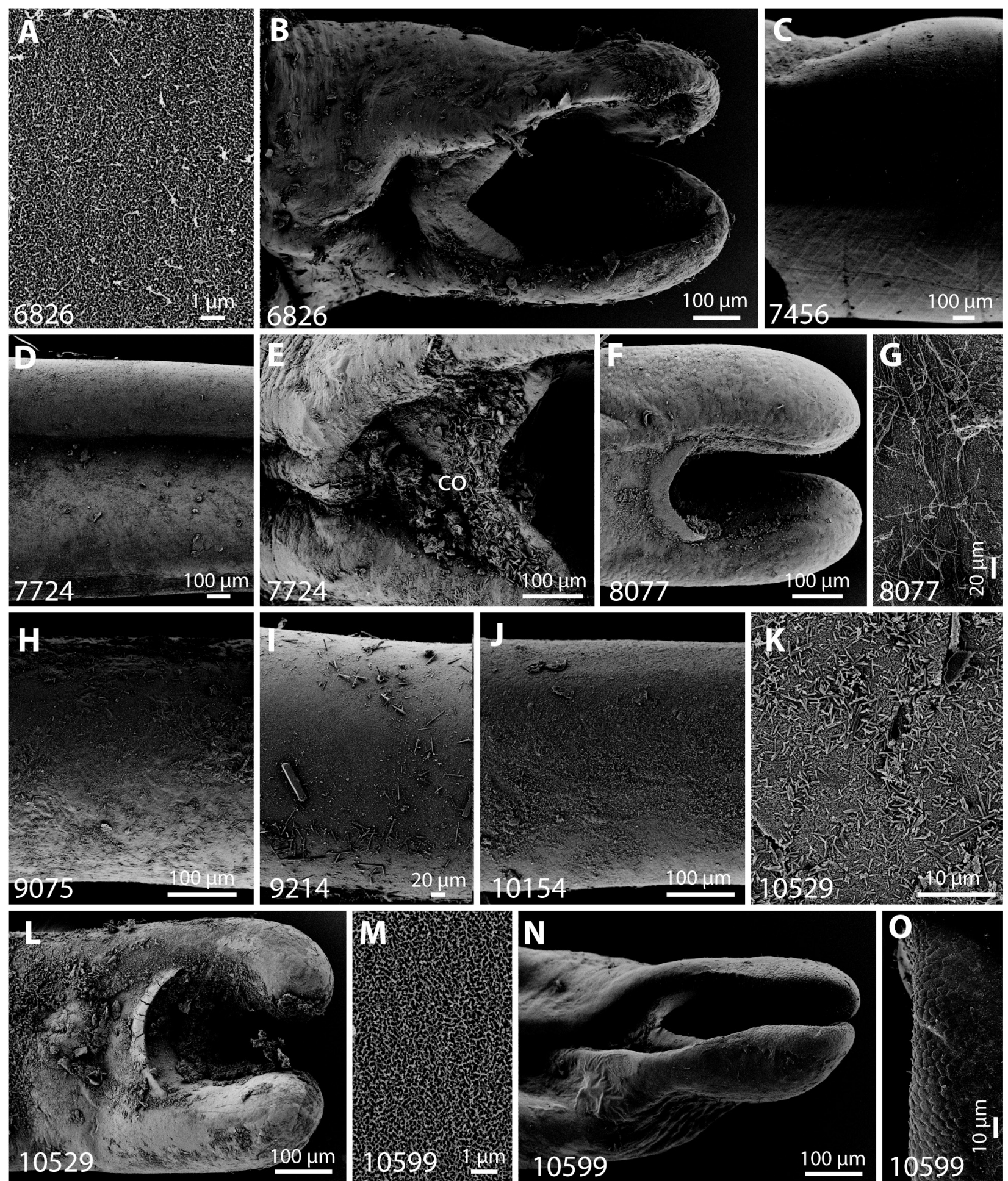

Figure 4. Specimens of Gordius sp., ventral view of posterior ends and cuticle in midbody sections. The specimen number is indicated in the lower left of each image. A, C, D, G, H-K, M. Cuticular surface, see text for explanation. B, E, F, L, N. Posterior ends with postcloacal crescent and cloacal opening (co). O. Areoles on the tail lobes of V10599. 

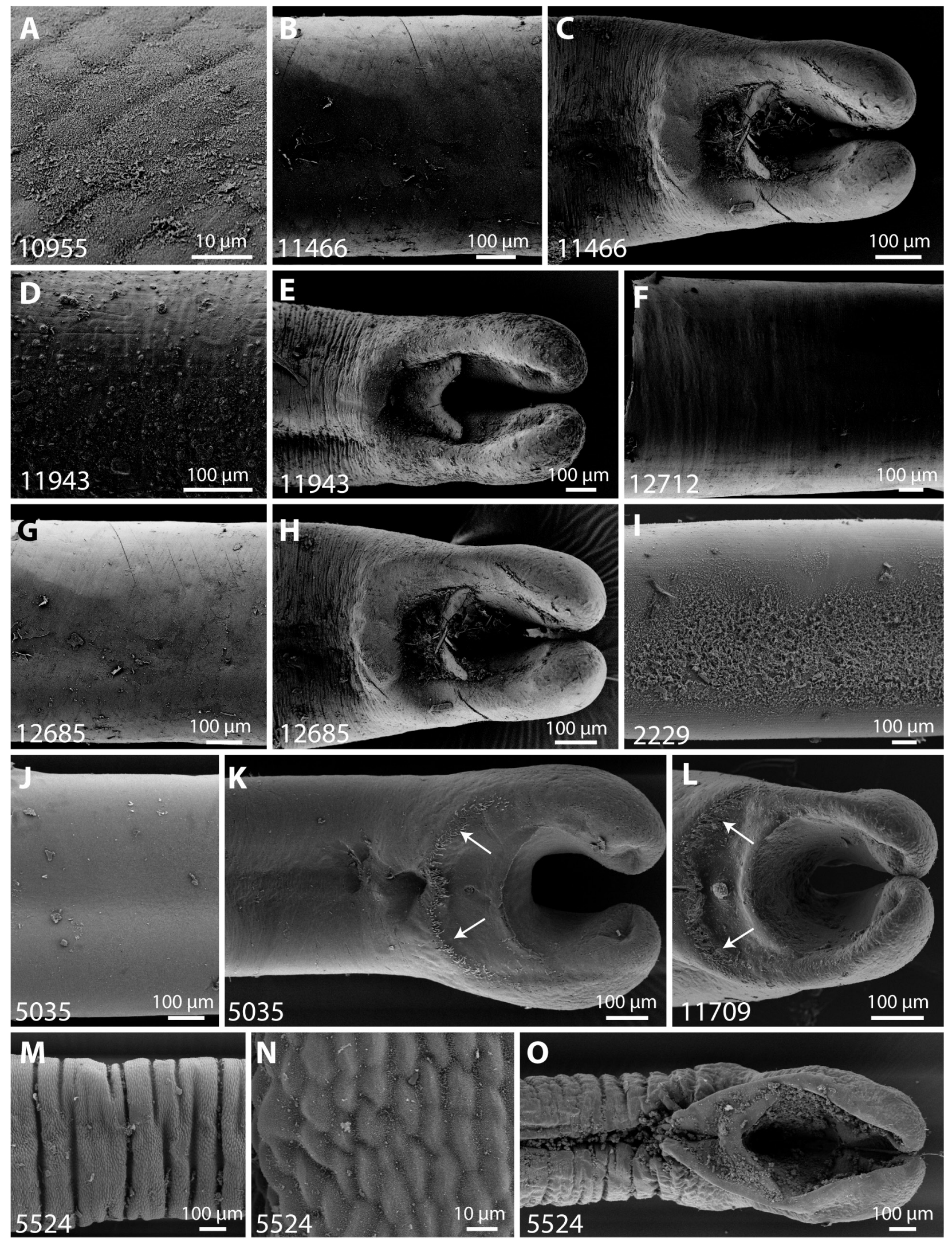

Figure 5. A-F. Specimens of Gordius sp., ventral view of posterior ends and cuticle in midbody sections. G, H. Gordius aquaticus (V12685), cuticle $(\mathbf{G})$ and posterior end (H). I. Cuticular surface of G. longissimus (V2229). J, K. Cuticle (J) and posterior end (K) of G. paranensis (V5035). Note row of bristles on the posterior end (arrows in K). L. Posterior end of G. paranensis (V11709), arrows as in K. M-O. Cuticle (M, N) and posterior end (O) of G. plicatissimus. The specimen number is indicated in the lower left of each image. 


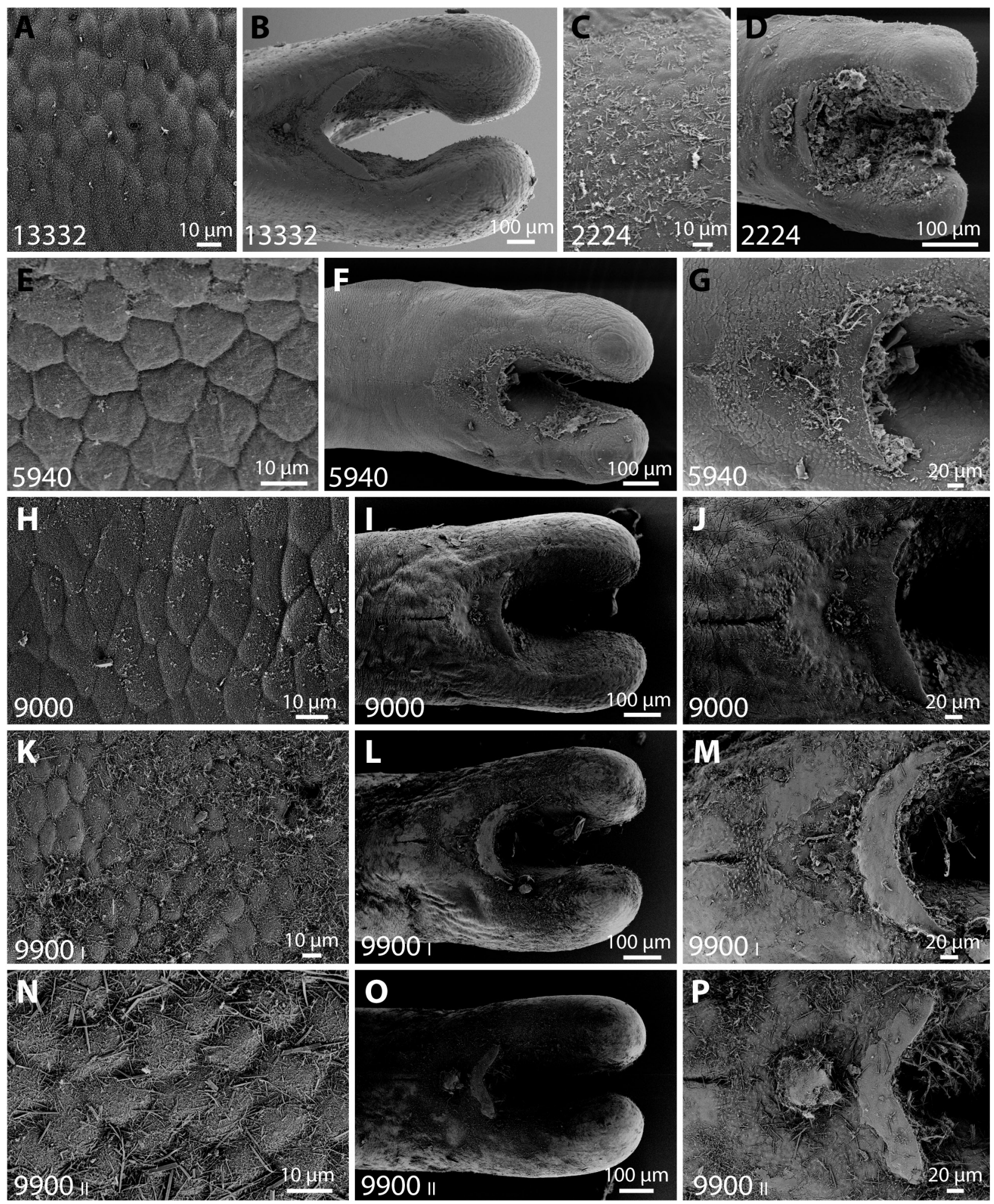

Figure 6. A, B. Cuticle (A) and posterior end (B) of Gordius plicatissimus (V13332). C-G. Gordius setiger, specimens V2224 (C, D) and V5940 (E-G). H-P. Gordius cf. setiger, specimens V9000 (H-J), V9900 male I (K-M) and V9900 male II (N-P). 

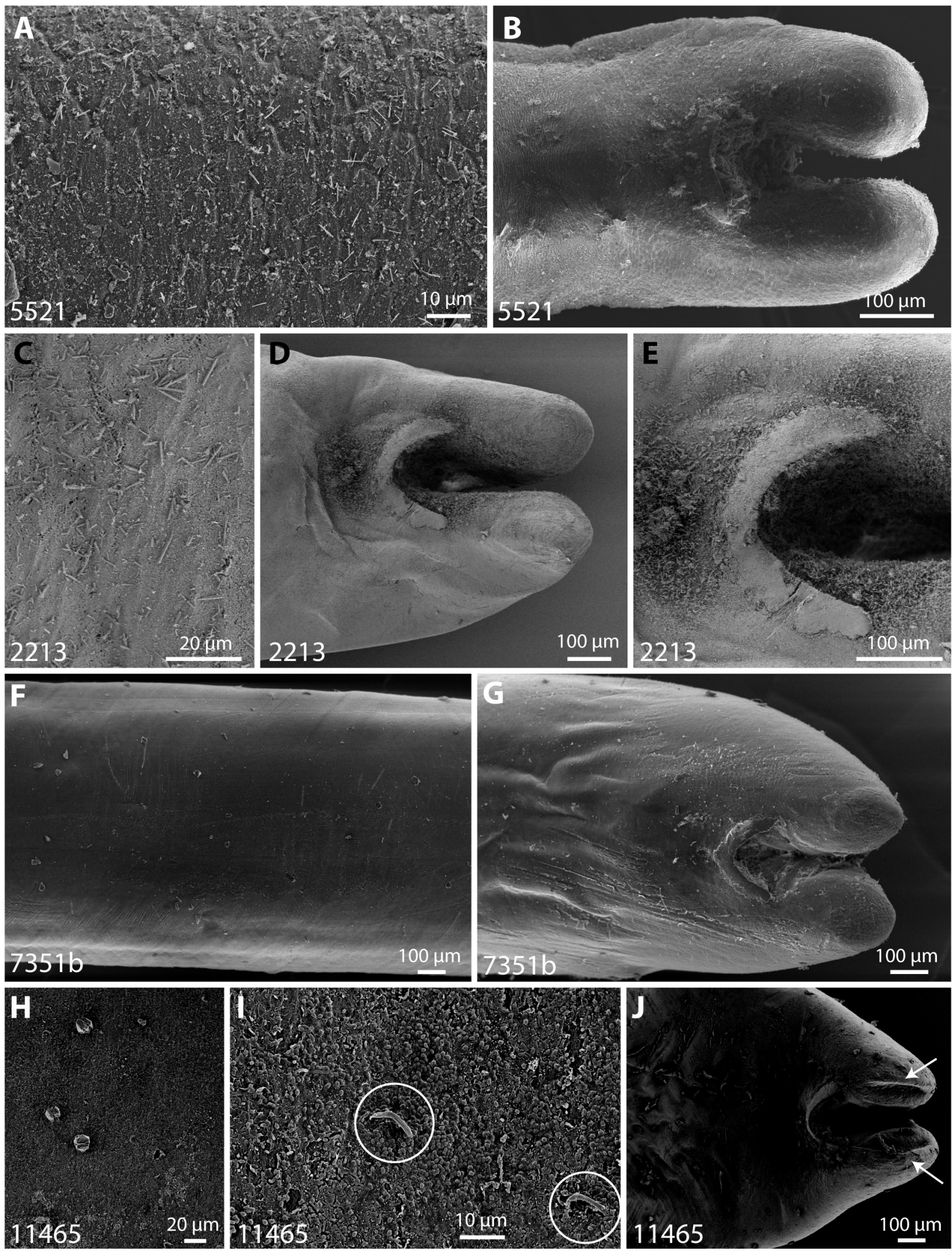

Figure 7. A, B. Cuticle (A) and posterior end (B) of Gordius undulatus (V5521). C-J. Acutogordius cf. acuminatus, specimens V2213 (C-E), V7351b (F, G) and V11465 (H-J). Note longitudinal crests or keels on tail lobes of V11465 (arrows in J) and scattered bristle-like structures on the cuticle (circles in $\mathbf{I}$ ) of the same specimen (see text). 


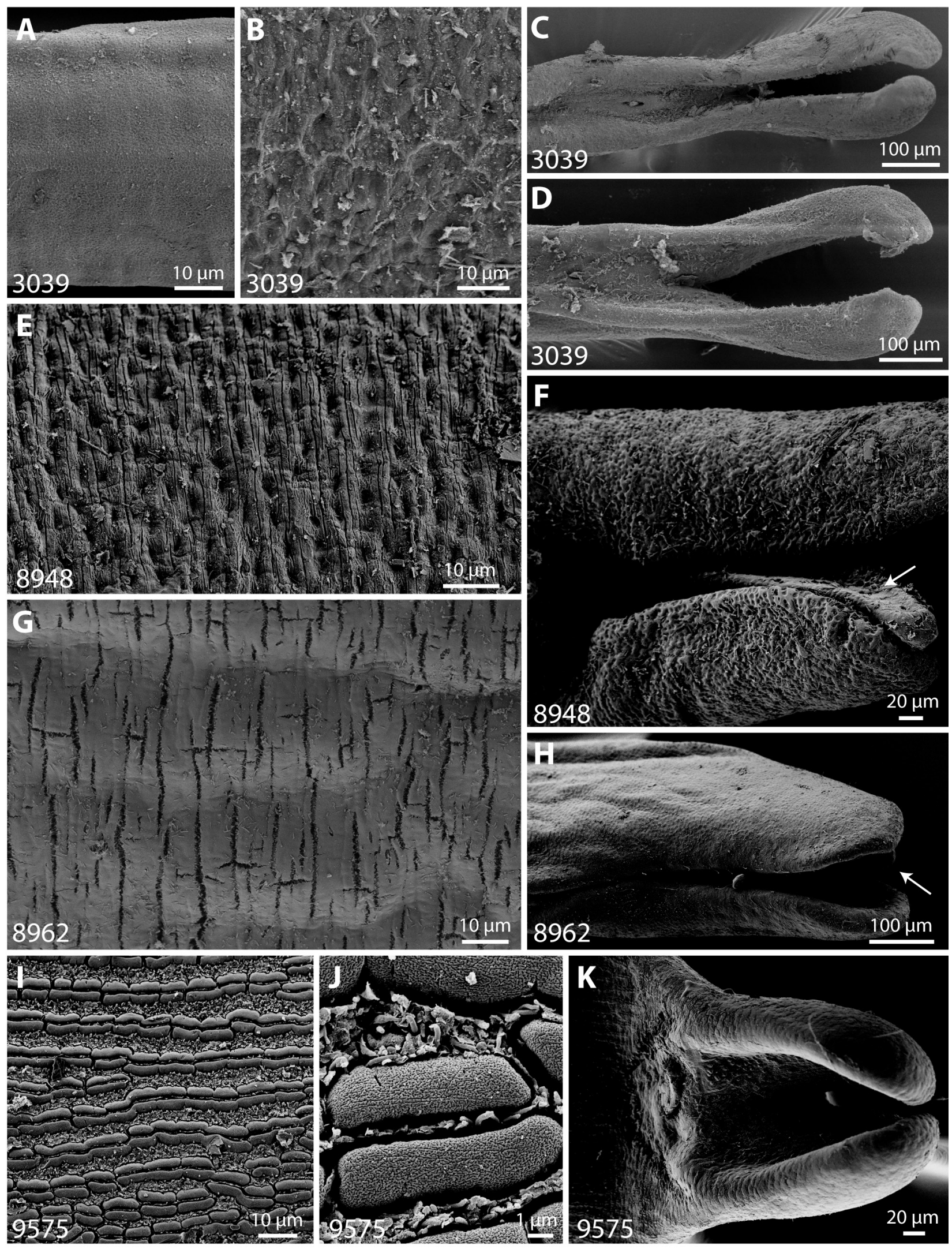

Figure 8. A-H. Paragordius sp., details of cuticle (A, B, E, G) and shape of the posterior ends of males (C, D; V3039) and females (F; V8948 and H; V8962). Arrow in F and $\mathbf{H}$ indicates the dorsal lobe. I-K. Beatogordius sp., longitudinal row of areoles (I), magnification of areoles $(\mathbf{J})$ and posterior end $(\mathbf{K})$. 

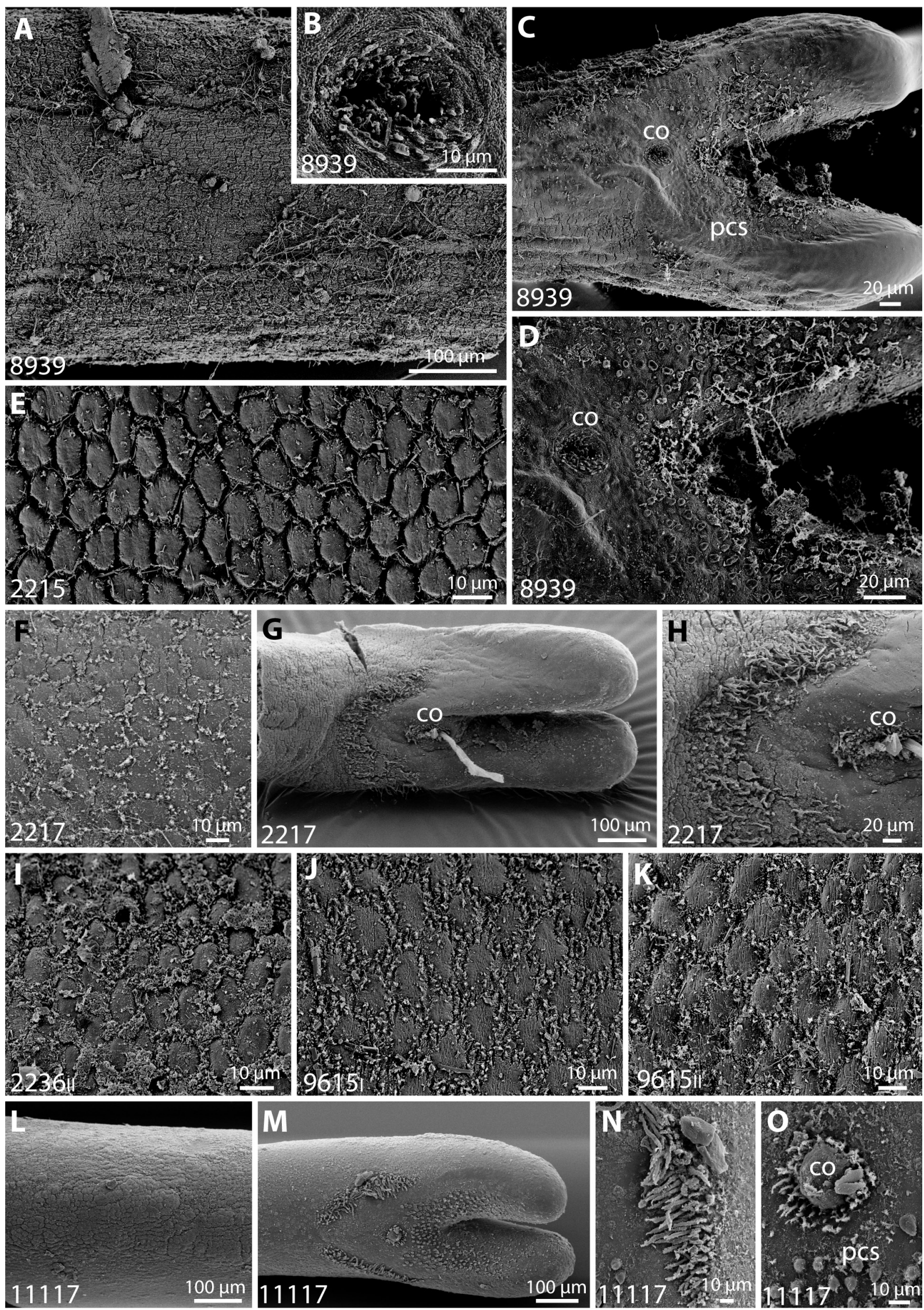

Figure 9. A-D. Beatogordius sp., cuticular pattern (A), detail of the cloacal opening (B), overview (C) and detail (D) of the posterior end, showing the cloacal opening (co) and the postcloacal spines (pcs). E-O. Gordionus sp., cuticular pattern and posterior ends of specimens V2215, V2217, V2236 (II), two specimens of V9615 (I and II) and V11117. H shows detail of precloacal bristles anterior to the cloacal opening (co). $\mathbf{N}$ shows precloacal bristles, $\mathbf{O}$ shows the cloacal opening (co) and some postcloacal spines (pcs). 


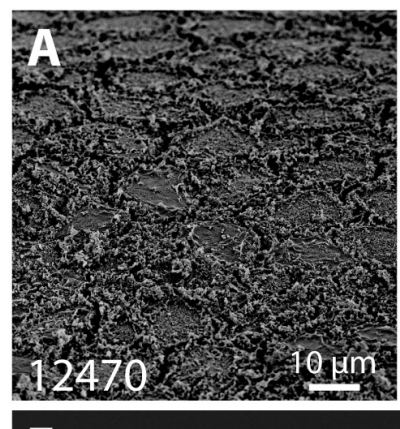

$\mathbf{E}$

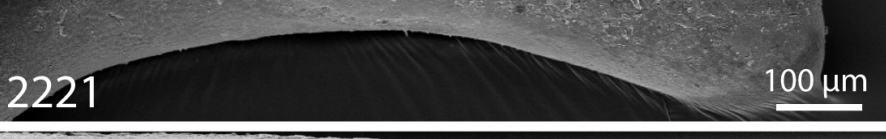

G

10924

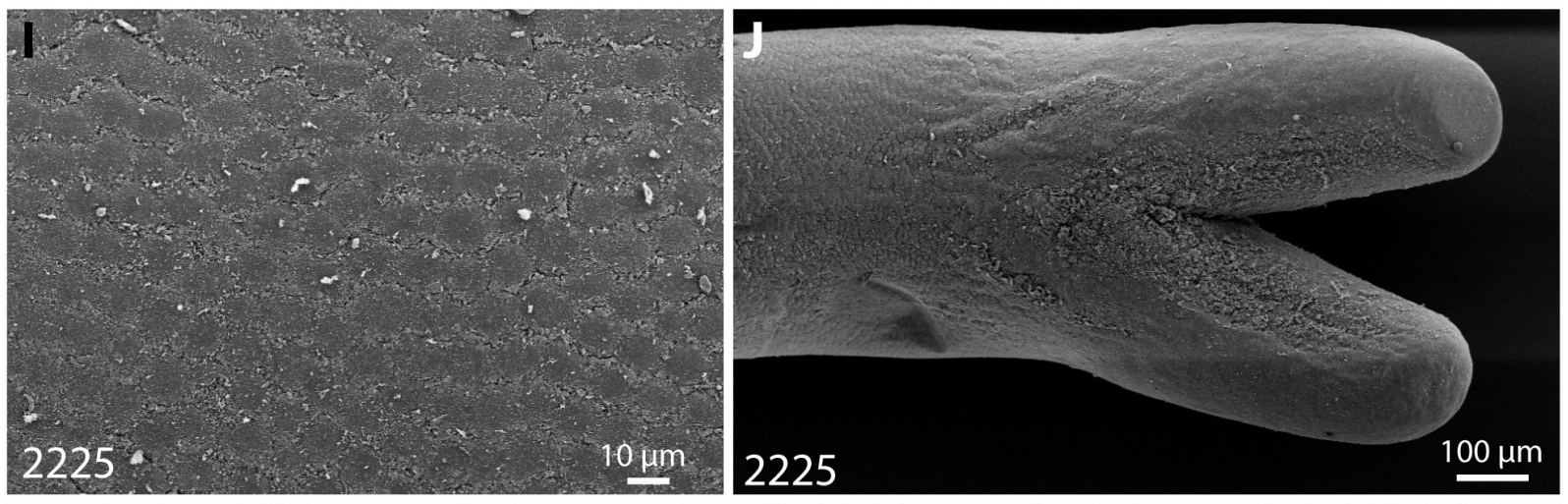

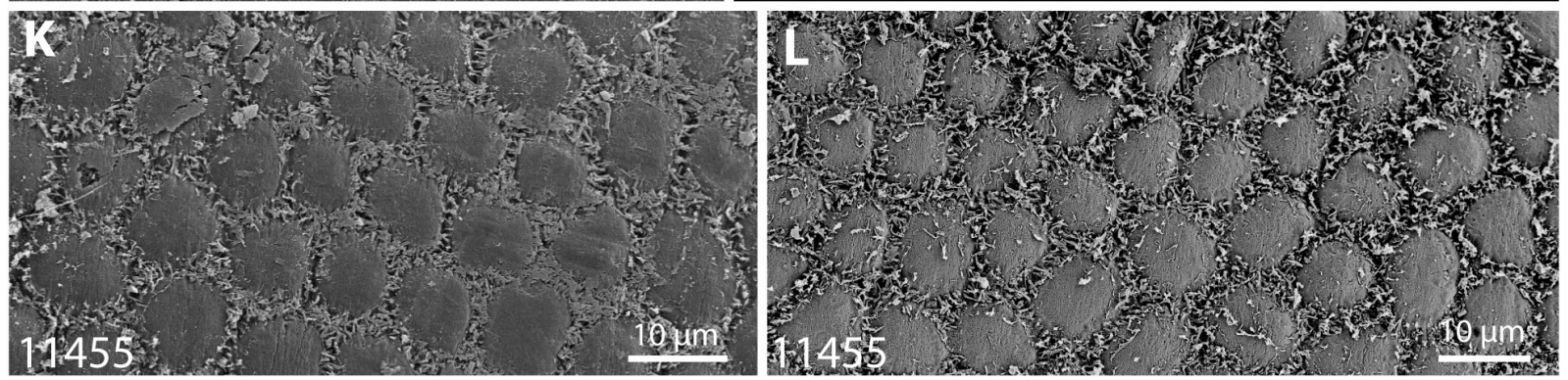

Figure 10. A-C. Cuticular surface of three specimens of Gordionus sp. (V12470, V13361, V13362). D-H. Gordionus scaber. Cuticular surface (D) and posterior end (E) of V2221, posterior end (G), magnification $(\mathbf{F})$ and detail from the precloacal bristles $(\mathbf{H})$ from V10924. I-L. Gordionus violaceus. Cuticular surface (I) and posterior end (J) of V2225, cuticular structure of two females of $\mathrm{V} 11455(\mathbf{K}, \mathbf{L})$ 

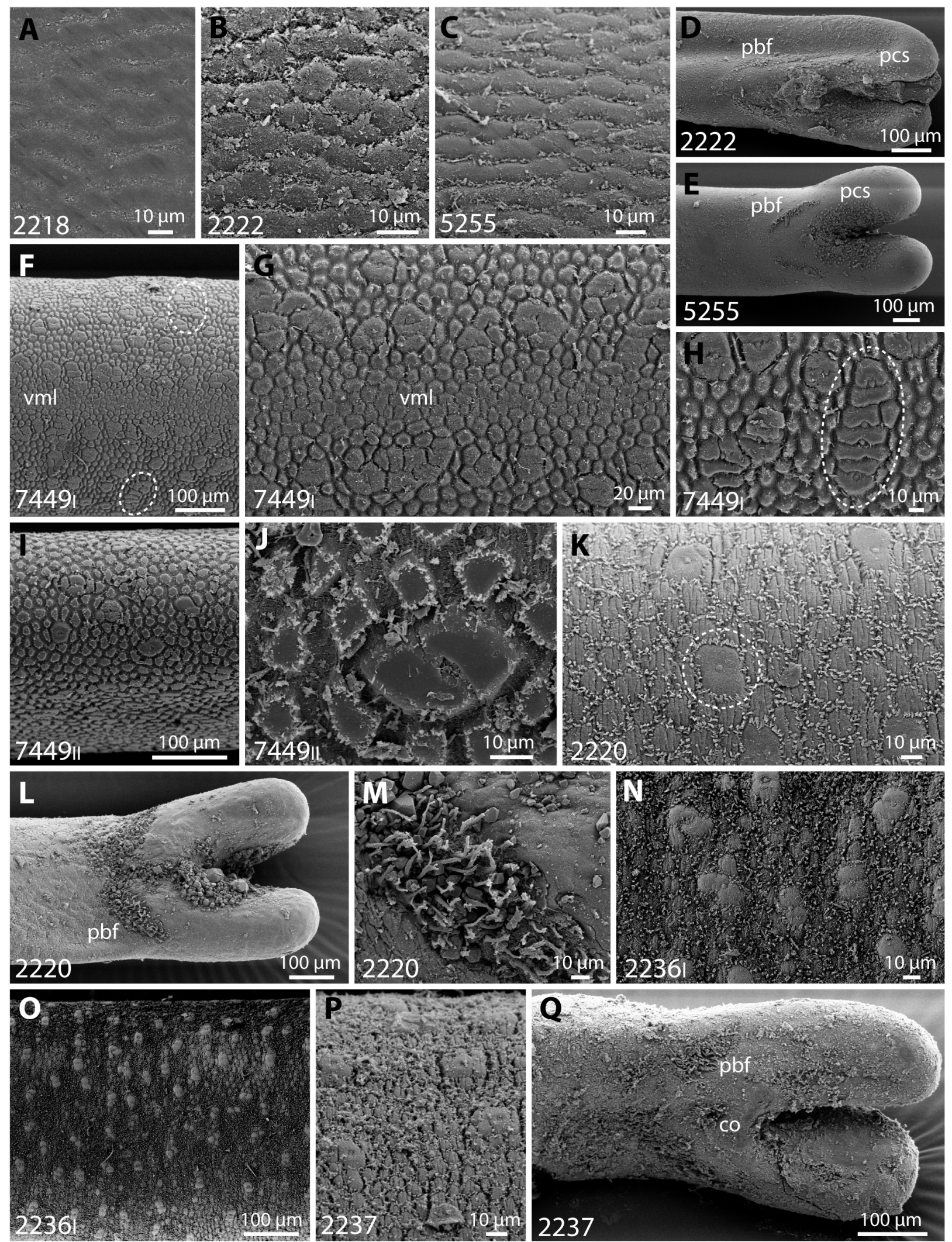

Figure 11. A-E. Gordionus wolterstorffi, cuticular surface (A-C) and posterior end (D, E) in specimens V2218, V2222 and V5255. Posterior end with precloacal bristlefields (pbf) and postcloacal spines (pcs). F-H. Paragordionus vejdovskyi, pattern of areoles on the cuticle. F. Overview with ventral midline (vml) and two types of areoles, simple areoles and larger megareoles in clusters (two of these are encircled). G. Maginification from F. H. Large cluster (encircled) of megareoles. I, J. Paragordionus dispar with smaller clusters of megareoles. K-Q. Parachordodes tolosanus. K. Superareoles, which are characteristic for Parachordodes, are encircled. L. Posterior end of V2220 with precloacal bristlefields (pbf), M. Magnification of precloacal bristlefields. N, O. Cuticular structure of V2236I with superareoles. P. Cuticle of V2237, Q. Posterior end of V2237 with precloacal bristlefields (pbf) and cloacal opening (co). 

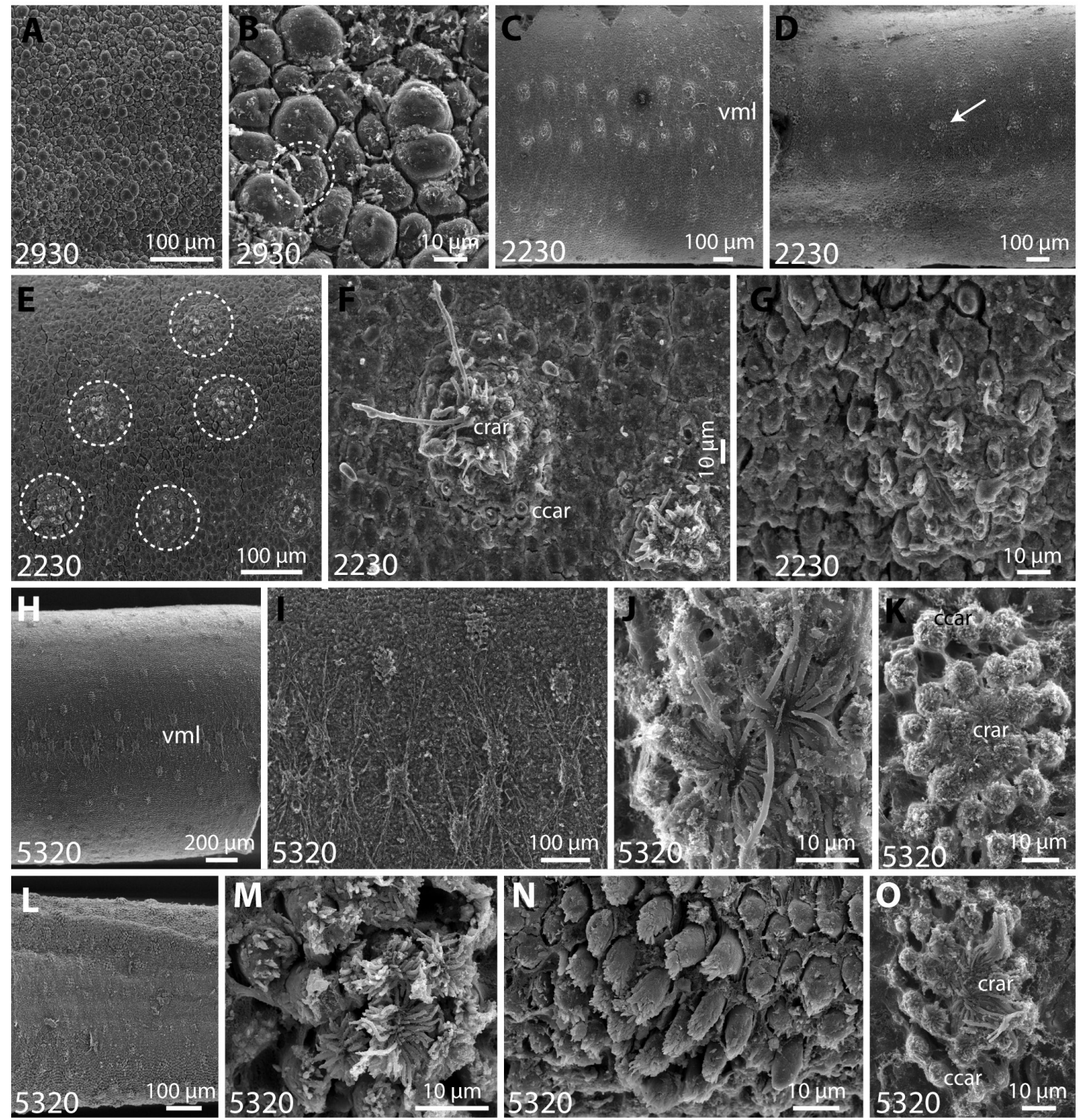

$100 \mathrm{um}$
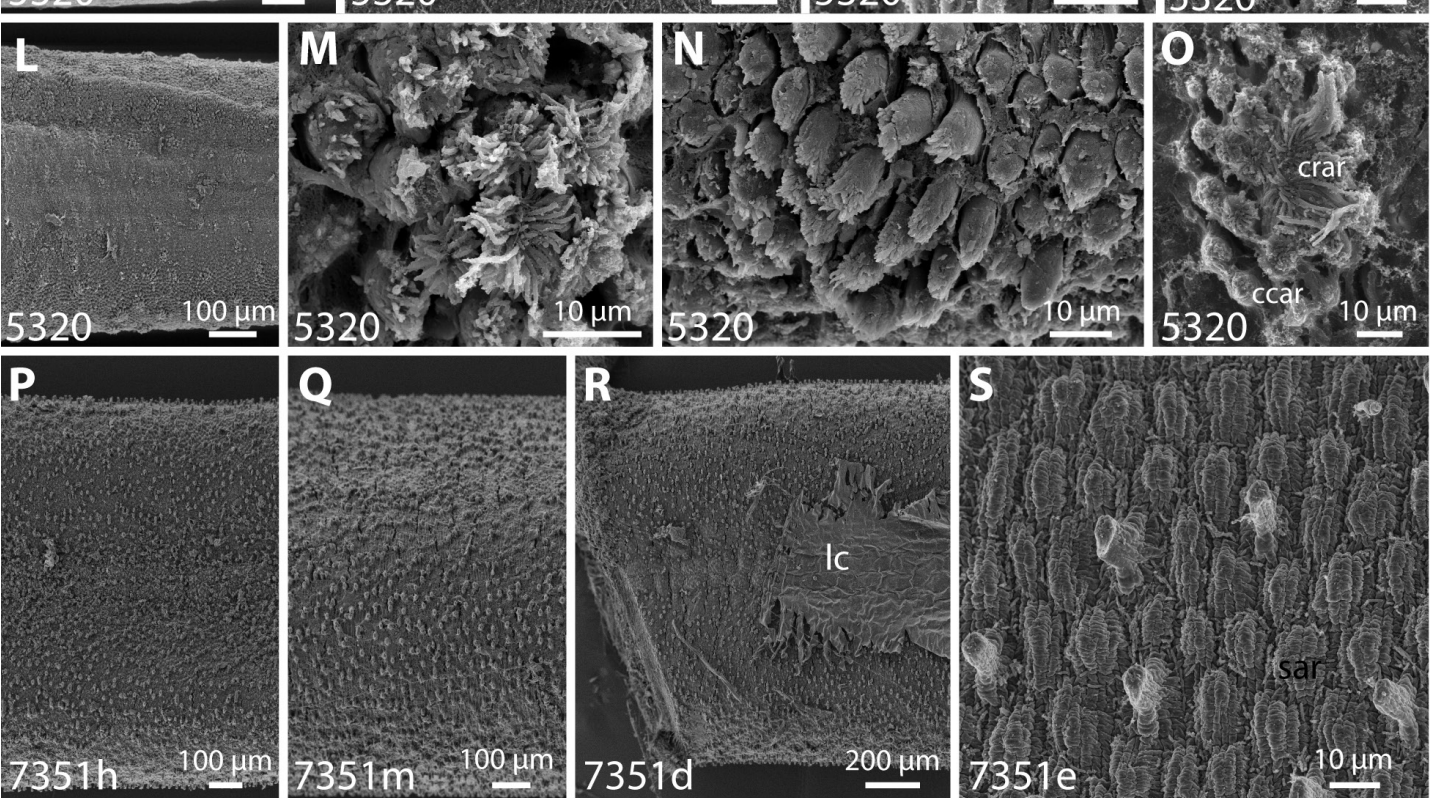

Figure 12. A, B. Pseudochordodes meridionalis, V2930. Cuticular structure in low (A) and higher (B) magnification, encircled in B is a tubercle areole. C-O. Chordodes sp., specimen V2230 (C-G) was formerly designated as holotype of C. pilosus. C. Overview onto the ventral side. Note elevated clusters on both sides of the ventral midline (vml). D. Overview onto the lateral side. Note scattered elevated clusters (arrow indicates one of these clusters). E. Higher magnification shows that the clusters are composed of elevated areoles. F. Clusters of crowned areoles (crar) and circumcluster areoles (ccar) are strongly eroded. Image shows a cluster from next to the ventral midline which includes crowned areoles with long apical filaments. G. Strongly eroded cluster from the lateral body side. H-O. Specimen V5320; H-K female specimen, L-O male specimen. H, I. Arrangement of crowned areole clusters with long filaments next to the ventral midline (vml). J. Two central crowned areoles within a cluster. K. Crowned areoles (crar) surrounded by circumcluster areoles (ccar). L-O. Cuticle and areoles in the male, see female for abbreviations. P-S. Chordodes brasiliensis, different specimens of number V7351. Cuticle shows scattered elevated crowned areoles among simple areoles (sar). Specimen V7351d has part of the cuticle covered by rests of the larval cuticle (lc). 

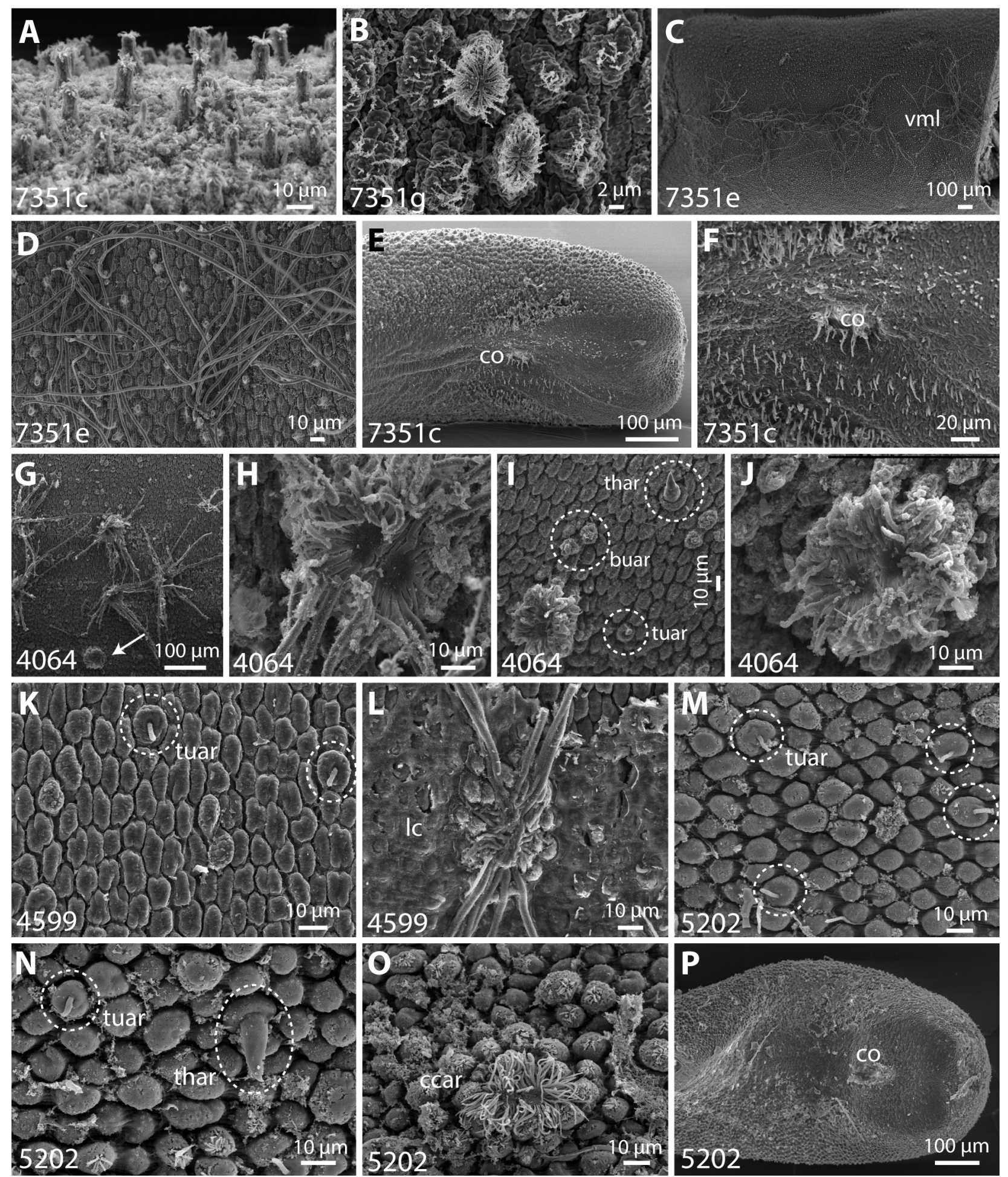

Figure 13. A-F. Chordodes brasiliensis, different specimens of number V7351. A, B. Higher magnification of crowned areoles. C, D. Crowned areoles with long apical filaments along the ventral midline (vml) in female specimen V7351e. E, F. Posterior end of a male (V7351c) with cloacal opening (co) and bristles around and in the region of the opening. G-J. C. jandae or C. skorikovi. G. Cuticular structures on the ventral side showing crowned areoles clusters with long filaments along the ventral midline and adjacent transition to clusters with short filaments (arrow). H, J. Magnification of crowned areoles. I. Different types of areoles: besides simple and crowned areoles (shown but not marked) there are bulging areoles (buar), thorn areoles (thar) and tubercle areoles (tuar). K, L. Chordodes japonensis, cuticular structure with tubercle areoles (tuar, encircled). Part of the cuticle is covered with larval cuticle (lc). M-P. Chordodes cf. japonensis, cuticle with different types of areoles: tubercle areoles (tuar, encircled in M), thorn areoles (thar) and circumcluster areoles (ccar) surrounding crowned areoles. Posterior end with cloacal opening (co). 

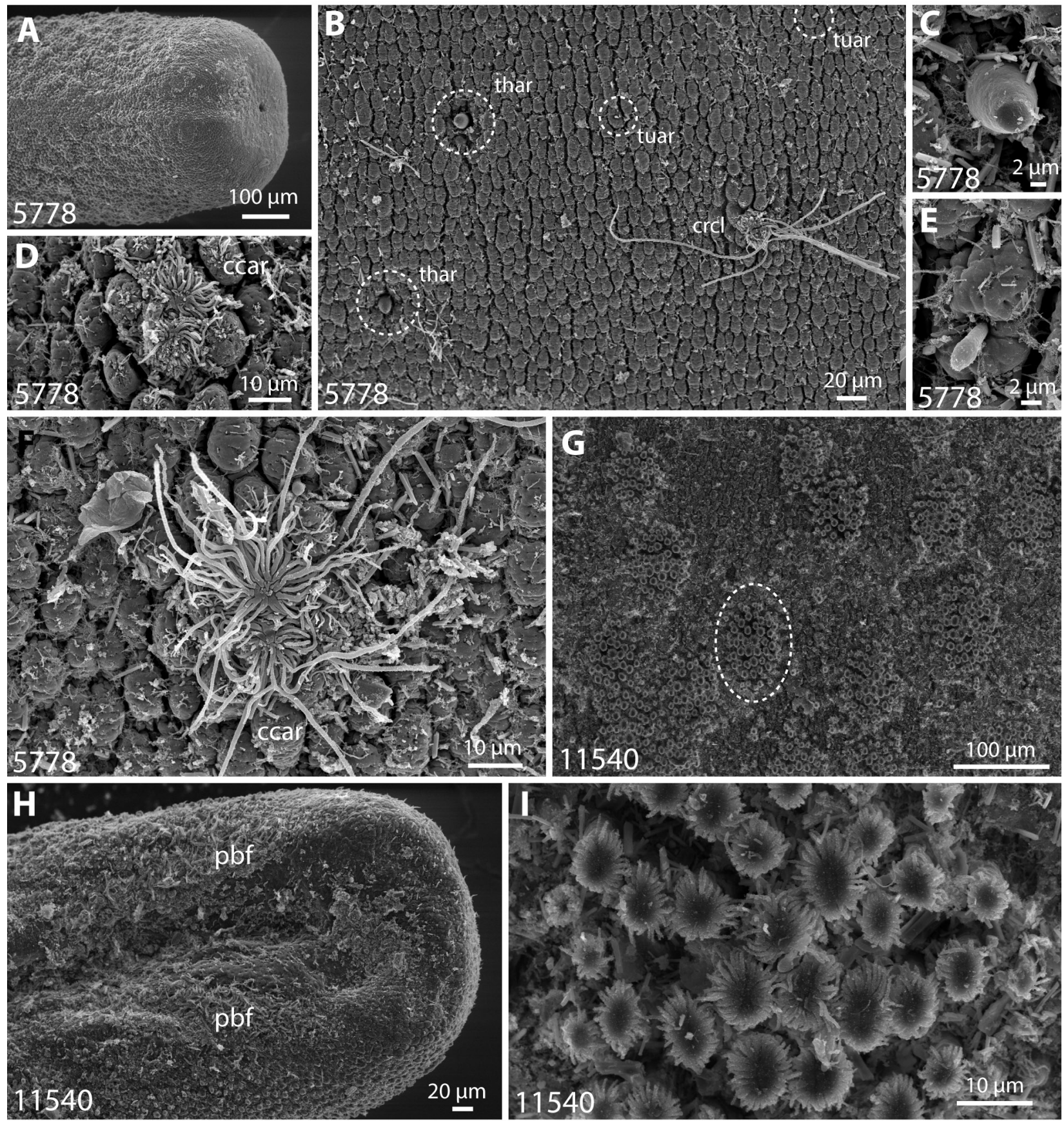

Figure 14. A-F. Chordodes cf. joyeuxi. A. Female posterior end with terminal cloacal opening. B. Overview on cuticle with different types of areoles: tubercle areoles (tuar), thorn areoles (thar) and cluster of crowned and circumcluster areoles (crcl) (here a cluster with long filaments is present). C. Magnification of thorn areoles. E. Magnification of tubercle areoles. D, F. Clusters of central crowned areoles and circumcluster areoles (ccar). G-I. Chordodes polycoronatus. G. Abundant large crowned areole clusters (one cluster is encircled). H. Posterior end with precloacal bristlefields (pbf). I. Magnification showing similar structure of areoles in the clusters. 

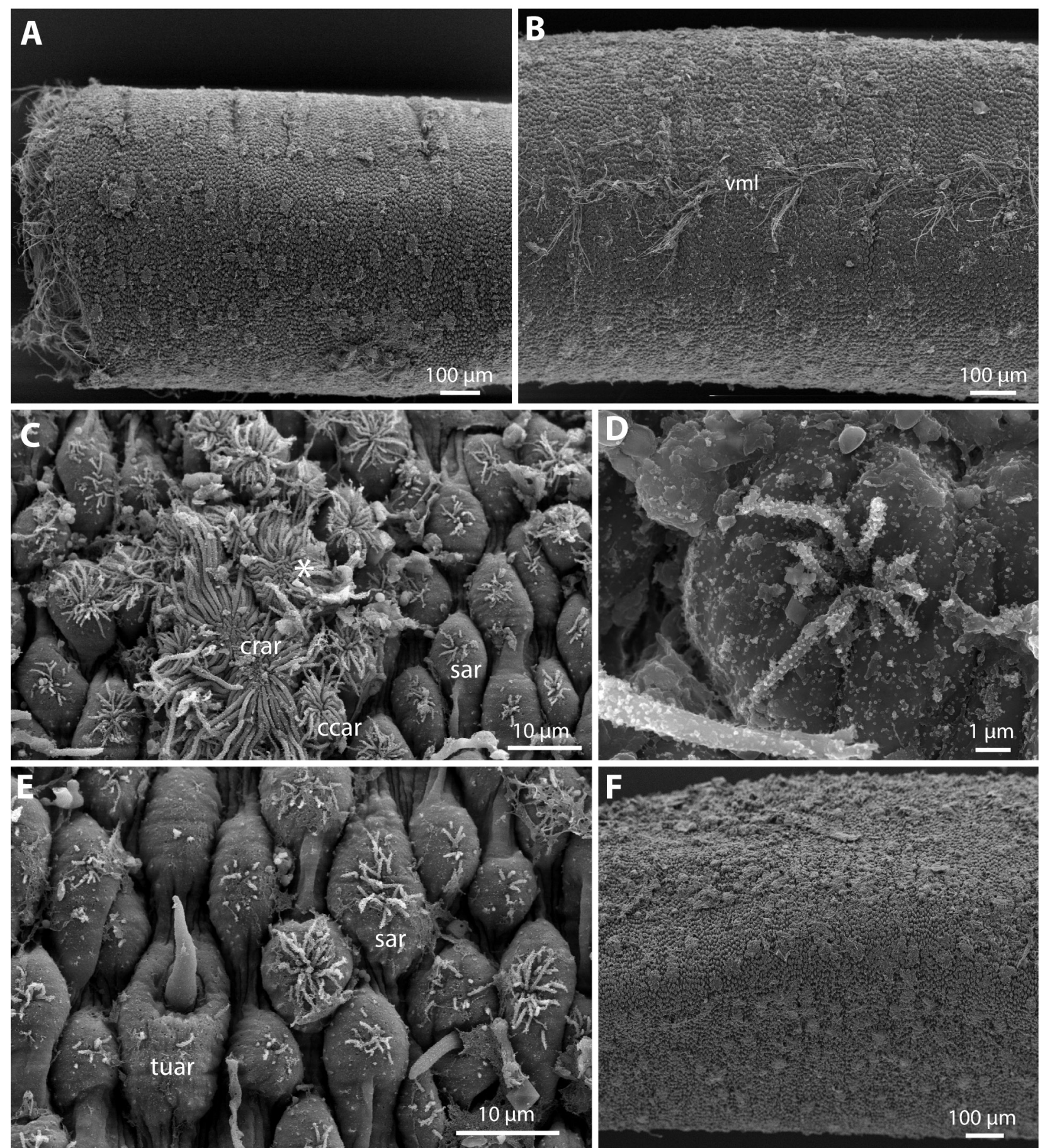

Figure 15. Chordodes jelkae sp. n.; A-E from holotype (V10960I). A. Overview on the cuticle from the lateral side showing elevated crowned areole clusters. B. Overview of the cuticle from the ventral side showing clusters with crowned areoles with long filaments along the ventral midline (vml). C. Fine structure of simple areoles (sar), crowned areoles (crar) and circumcluster areoles (ccar). Some areoles may be either type $\left(^{*}\right)$. D. Magnification of simple areoles. E. Arrangement of simple areoles (sar) and structure of tubercle areoles (tuar). F. Cuticle from second specimen (V10960II). 

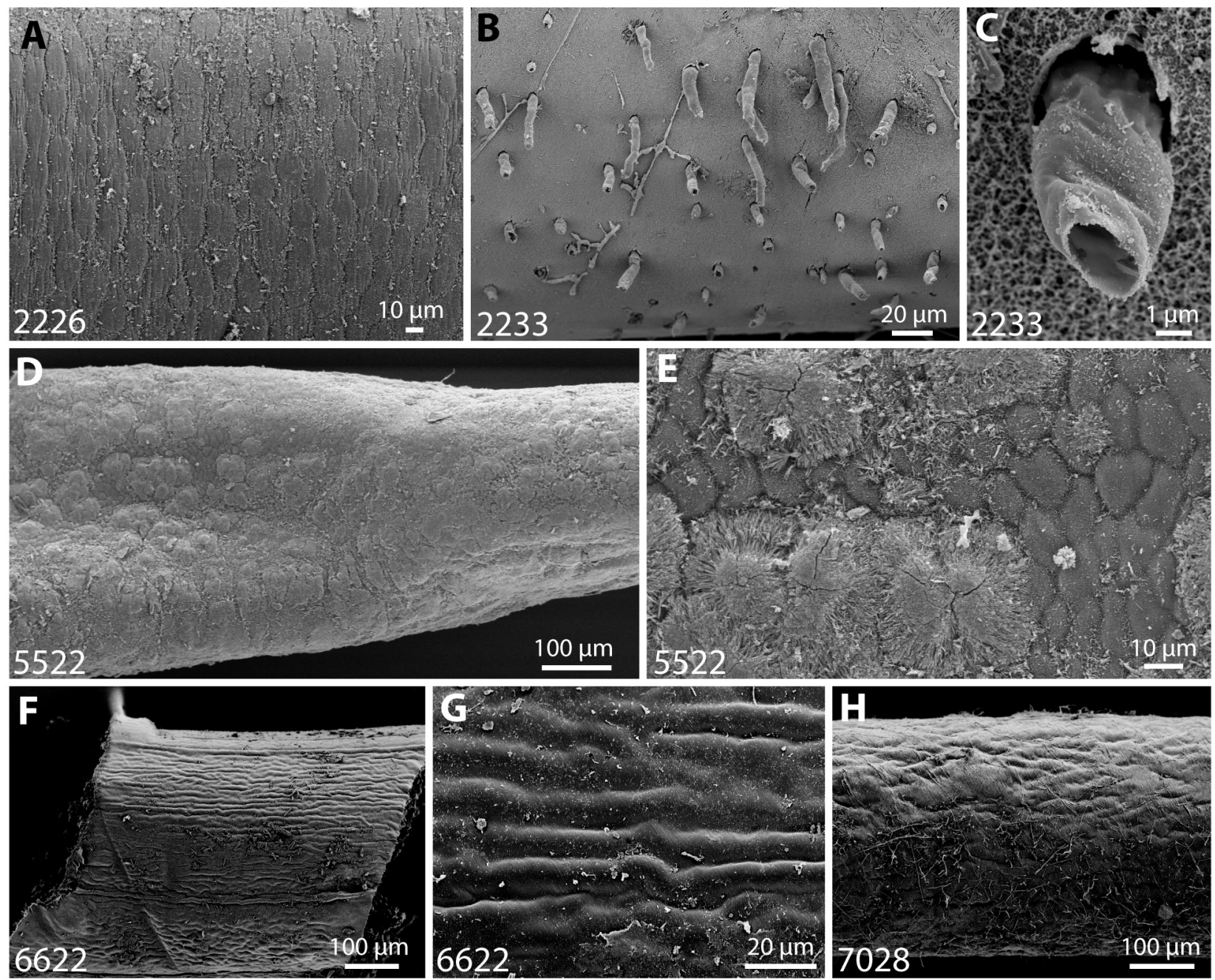

Figure 16. Undetermined specmens. A. Areoles in V2226. B, C. Tubular structures in V2233. D, E. Encrusting material on V5522. F, G. Cuticle in V6622. H. Cuticle in V7028.

\section{Acknowlegements}

Two persons have helped very much during this project. Vladimira Oldenburg made most of the SEM investigation during a student project. Helma Roggenbuck took care of handling the collection and updating everything according to new results. Many thanks to both of them.

\section{References}

Bolek MG, Schmidt-Rhaesa A, Hanelt B, Richardson DJ (2010) Redescription of the African Chordodes albibarbatus Montgomery, 1898, and description of Chordodes janovyi n. sp. (Gordiida, Nematomorpha) and its non-adult stages from Cameroon, Africa. Zootaxa 2631: 36-50.

Camerano L (1897) Monografia dei Gordii. Memoire della Reale Accademia delle Science di Torino 47: 339-415.

Carvalho JCM, Feio JLA (1950) Sōbre alguns Gordiáceos do Brasil e da Republica Argentina (Nematomorpha, Gordioidea). Anais da Academia Brasileira de Ciências 22: 193-216.

Creplin CH (1847) Chordodes parasitus, ein Schmarotzerwurm aus einer Heuschrecke. Notizen aus dem Gebiete der Natur- und Heilkunde 3: 161-166.
De Miralles DB, De Villalobos LC (1996) Especies de Neochordodes de la Argentina (Gordiacea, Nematomorpha). Iheringia, Sér. Zool. 81: $145-150$.

De Miralles DB, De Villalobos LC (1998) Dos nuevas especies y una nueva combinación para el género Acutogordius (Nematomorpha: Gordiidae). Neotropica 44: 75-79.

De Villalobos LC, Schmidt-Rhaesa A, Zanca F (2003) Revision of the genus Beatogordius (Gordiida, Nematomorpha). II. South American species with description of two new species. Memorias do Instituto Oswaldo Cruz 98: 115-128. doi: 10.1590/S007402762003000100015

De Villalobos C, Zanca F, Ibara-Vidal H (2005) Redescription and new records of freshwater Nematomorpha (Gordiida) from Chile, with the description of two new species. Revista Chilena de Historia Natural 78: 673-686. doi: 10.4067/S0716-078X2005000400007

De Villalobos C, Zanca F, Salas L (2008) Especies de Gordiida (Nematomorpha) en la Provincia de Catamarca. Ciencia 3: 47-56.

De Villalobos C, Zanca F, Schmidt-Rhaesa A (2004) New data on South American species of Chordodes (Nematomorpha). Arquivos do Museu Nacional, Rio de Janeiro 62: 375-386.

Hanelt B, Bolek MG, Schmidt-Rhaesa A (2012) Going solo: Discovery of the first parthenogenetic gordiid (Nematomorpha: Gordiida). PLoS ONE 7: e34472. doi: 10.1371/journal.pone.0034472 
Hanelt B, Thomas F, Schmidt-Rhaesa A (2005) Biology of the Phylum Nematomorpha. Advances in Parasitology 59: 243-305. doi: 10.1016/S0065-308X(05)59004-3

Heinze K (1933) Revision von Gordius flavus Linstow 1906 und Gordius flavus G.W. Müller 1927. Zoologischer Anzeiger 105: 106-109.

Heinze K (1934) Zur Systematik der Gordiiden. Zoologischer Anzeiger 106: 189-192.

Heinze K (1935a) Über Gordiiden (Species inquirendae und Neubeschreibungen). Zoologischer Anzeiger 111: 23-32.

Heinze K (1935b) Über das Genus Parachordodes Camerano 1897 nebst allgemeinen Angaben über die Familie Chordodidae. Zeitschrift für Parasitenkunde 7: 657-678. doi: 10.1007/BF02121327

Heinze K (1937) Die Saitenwürmer (Gordioidea) Deutschlands. Eine systematisch-faunistische Studie über Insektenparasiten aus der Gruppe der Nematomorpha. Zeitschrift für Parasitenkunde 9: 263-344. doi: 10.1007/BF02119887

Heinze K (1941) Saitenwürmer oder Gordioidea (Nematomorpha). In Dahl F (ed). Die Tierwelt Deutschlands und der angrenzenden Meeresteile. Gustav Fischer Verlag, Jena, 1-78.

Heinze K (1952) Über Gordioidea, eine systematische Studie über Insektenparasiten aus der Gruppe der Nematomorpha. Zeitschrift für Parasitenkunde 15: 183-202.

Inoue I (1952) On a new species of Chordodes (Gordiacea) from Japan. Annotationes Zoologicae Japonensis 25: 400-402.

Janda J (1894) Beiträge zur Systematik der Gordiiden. I. Die Gordiiden Galliziens. - II. Ueber das Genus Chordodes. Zoologische Jahrbücher. Abteilung für Systematik, Geographie und Biologie der Tiere 7: 595-612.

Kintsurashvili N, Schmidt-Rhaesa A, Gorgadze O (2011) Chordodes parabipilus (Nematomorpha: Gordiida), a new species of horsehair worms from Georgia. Verhandlungen des Naturwissenschaftlichen Vereins in Hamburg 46: 235-241.

Möbius K (1855) Chordodes pilosus, ein Wurm aus der Familie der Gordiaceen. Zeitschrift für Wissenschaftliche Zoologie 6: 428-431.

Müller GW (1926) Über Gordiaceen. Zeitschrift für Morphologie und Ökologie der Tiere 7: 134-220. doi: 10.1007/BF00540721

Römer F (1895) Die Gordiiden des Naturhistorischen Museums in Hamburg. Zoologische Jahrbücher. Abteilung für Systematik 8: 790-803.

Römer F (1896) Beitrag zur Systematik der Gordiiden. Abhandlungen der Senckenbergischen Naturforschenden Gesellschaft 23: 249-295.

Sato T, Watanabe K, Tamotsu T, Ichikawa A, Schmidt-Rhaesa A (2012) Diversity of nematomorphs and cohabiting nematode parasites in riparian ecosystems around Kii Peninsula, Japan. Canadian Journal of Zoology 90: 829-838. doi: 10.1139/z2012-048

Schmidt-Rhaesa A (1997) Nematomorpha. In: Schwoerbel J, Zwick P (Eds) Süßwasserfauna Mitteleuropas. Gustav Fischer Verlag, Stuttgart, 1-124.

Schmidt-Rhaesa A (2001) Variation of cuticular characters in the Nematomorpha: studies on Gordionus violaceus (Baird, 1853) and G. wolterstorffii (Camerano, 1888) from Britain and Ireland. Systematic Parasitology 49: 41-57. doi: 10.1023/A:1010600200665

Schmidt-Rhaesa A (2002a) Are the genera of Nematomorpha monophyletic taxa? Zoologica Scripta 31: 185-200. doi: 10.1046/j.14636409.2002.00073.x

Schmidt-Rhaesa A (2002b) Australian species of Chordodes (Nematomorpha) with a description of two new species, remarks on the genus and its life history. Journal of Natural History 36: 1569-1588. doi: 10.1080/00222930110059664
Schmidt-Rhaesa A (2004) Japanese horsehair worms (Nematomorpha) from the Lake Biwa Museum. Species Diversity 9: 97-107.

Schmidt-Rhaesa A (2005) Morphogenesis of Paragordius varius (Nematomorpha) during the parasitic phase. Zoomorphology 124: 33-46. doi: 10.1007/s00435-005-0109-z

Schmidt-Rhaesa A (2010) Considerations on the genus Gordius (Nematomorpha, horsehair worms), with the description of seven new species. Zootaxa 2533: 1-35.

Schmidt-Rhaesa A (2011) Beatogordius chinensis (Nematomorpha, Gordiida), a new species from China. Verhandlungen des Naturwissenschaftlichen Vereins in Hamburg 46: 243-248

Schmidt-Rhaesa A (2013) Nematomorpha. In: Schmidt-Rhaesa A (Ed.) Handbook of Zoology. De Gruyter, Berlin, 29-145.

Schmidt-Rhaesa A, Brune S (2008) Description of one known and three new Chordodes species (Nematomorpha) parasitizing praying mantids (Mantoptera) in Malaysia, with a discussion of sexual dimorphism in Chordodes. Zoosystematics and Evolution 84: 57-66. doi: 10.1002/zoos.200700014

Schmidt-Rhaesa A, Cieslak A (2008) Three new species of Paragordionus and Gordionus (Nematomorpha, Gordiida) from Spain and Turkey, with comments on the taxon Semigordionus. Mitteilungen aus dem Hamburgischen Zoologischen Museum und Institut 105: 13-22.

Schmidt-Rhaesa A, De Villalobos LC, Zanca F (2008) Summary of Chordodes species (Nematomorpha, Gordiida), with a discussion of their diagnostic characters. Verhandlungen des Naturwissenschaftlichen Vereins in Hamburg 44: 37-114.

Schmidt-Rhaesa A, Geraci CJ (2006) Two new species of Acutogordius (Nematomorpha), with a brief review of literature data of this genus. Biodiversity and Systematics 4: 427-433. doi: 10.1017/ S1477200006001964

Schmidt-Rhaesa A, Gusich VV (2010) A new Gordionus Müller, 1927 from Switzerland (Nematomorpha, Gordiida). Revue Suisse de Zoologie 117: 77-82. doi: 10.5962/bhl.part.117589

Schmidt-Rhaesa A, Hanelt B, Reeves W (2003) Redescription and compiliation of Nearctic freshwater Nematomorpha (Gordiida), with the description of two new species. Proceedings of the Academy of Natural Sciences of Philadelphia 153: 77-117. doi: 10.1635/0097-3157(2003)153[0077:RACONF]2.0.CO;2

Schmidt-Rhaesa A, Kieneke A, Muschiol D, Chung PR (2001) Tubular structures on the cuticle of two Gordius species (Nematomorpha, Gordioidea, Gordiidae) from Korea and New Zealand. Korean Journal of Systematic Zoology 17: 165-169.

Schmidt-Rhaesa A, Kristensen P (2006) Horsehair worms (Nematomrpha) from the Baltic Island Bornholm (Denmark), with notes on the biology of Gordius albopunctatus. Journal of Natural History 40: 495-502. doi: 10.1080/00222930600761803

Schmidt-Rhaesa A, Limatemjen, Yadav AK (2015) Chordodes combiareolatus, a new species of horsehair worms (Nematomorpha) from Nagaland, India, with further comments on Chordodes moutoni. Zootaxa 3925: 202-210. doi: 10.11646/zootaxa.3925.2.3

Schmidt-Rhaesa A, Prous M (2010) Records of horsehair worms (Nematomorpha) in Estonia, with description of three new species from the genus Gordius. Estonian Journal of Ecology 59: 39-51. doi: 10.3176/eco.2010.1.03

Schmidt-Rhaesa A, Sato T (2009) Gordionus chinensis (Villot, 1874) and Gordionus kii sp.n. (Nematomorpha, Gordiida), new reports of the genus Gordionus in Japan. Species Diversity 14: 61-67. 
Schmidt-Rhaesa A, Thomas F, Poulin R (2000) Redescription of Gordius paranensis Camerano, 1892 (Nematomorpha), a species new for New Zealand. Journal of Natural History 34: 333-340. doi: $10.1080 / 002229300299516$

Schmidt-Rhaesa A, Urabe M (2009) New records of Gordius specimens from Japan (Nematomorpha, Gordiida). Mitteilungen des Zoologischen Museums in Hamburg 106: 1-6.

Schmidt-Rhaesa A, Wagner FM (2013) Considerations on the genus Paragordionus (Nematomorpha, Gordiida). Verhandlungen des Naturwissenschaftlichen Vereins in Hamburg 47: 173-183.
Schmidt-Rhaesa A, Yadav A (2013) One new species and a new record of the genus Chordodes (Nematomorpha: Gordiida) from North-East India. Zootaxa 3693: 293-300. doi: 10.11646/zootaxa.3693.2.10

Von Siebold CT (1848) Ueber die Fadenwürmer der Insecten (Zweiter Nachtrag). Entomologische Zeitschrift 10 (9. Jahrgang): 290-300.

Zanca F, Schmidt-Rhaesa A (2006) Reinvestigation and new evaluation of representatives from the genera Semigordionus, Euchordodes, Pantachordodes, Dacochordodes and Spinochordodes (Nematomorpha). Mitteilungen aus dem Museum für Naturkunde in Berlin, Zoologische Reihe 82: 170-178. doi: 10.1002/mmnz.200600003 